\title{
Numerical modelling of the suspended particulate matter dynamics in a regulated river network
}

\author{
M. Launaya,b, V. Duguéa,c, J.-B. Faure ${ }^{\mathrm{a}}$, M. Coquery ${ }^{\mathrm{a}}$, B. Camenen ${ }^{\mathrm{a}}$, \\ J. Le Coz ${ }^{\mathrm{a}, 1}$ \\ ${ }^{a}$ Irstea, UR RiverLy, 5 rue de la Doua CS 20244, 69625 Villeurbanne Cedex, France \\ ${ }^{b}$ Now at Stucky SA, Rue du Lac 33, 1020 Renens VD, Switzerland \\ ${ }^{c}$ Now at CNR, Compagnie Nationale du Rhône, 2 rue André Bonin, 69004 Lyon, France
}

\begin{abstract}
Understanding and predicting the propagation, deposition and re-suspension of suspended particulate matter (SPM) in river networks is important for managing water resources, ecological habitat, pollution, navigation, hydropower generation, reservoir sedimentation, etc. Observational data are scarce and costly, and there is little feedback on the efficiency of numerical simulation tools for compensating the lack of data on a river scale of several hundreds of kilometres. This paper aims at exploring the use of a one-dimensional (1-D) hydrodynamical model for understanding the source and fate of SPM during complex events. The numerical model was applied to the May-June 2008 flood in the Lower Rhône River, France. This event was a combination of floods of the Isère (including dam flushing operations in the Lower Isère River) and Durance tributaries over a two-week period. The simulation code was used to model the SPM fluxes at a high spatial and temporal resolution using a multi-class approach. Approximately half of the $4.9 \mathrm{Mt}$ of SPM measured at the outlet at Beaucaire were found to come from the Isère River and the other half from the Durance River, whereas previous studies estimated that most of the SPM flux at the outlet came from the Durance River. The amount of SPM trapped within the river network, mainly behind the first hydropower structure downstream of the Isère confluence, was estimated to be $3.7 \mathrm{Mt}$ due to the deposition of the coarsest
\end{abstract}

* Corresponding author 
particles. Such a model proved to be able to compute the interaction of various grain size classes with dams and other structures. In turn, the quality of the results of SPM fluxes and deposition is highly sensitive to particle parameters, especially grain size distribution, and to the operational rules of reservoirs.

Keywords: suspended sediment, suspended solids, 1-D hydrodynamical model, numerical simulation, Rhône River, flood

\section{Introduction}

Monitoring the suspended particulate matter (SPM) dynamics in river systems is crucial for multiple environmental management issues, such as the ecological restoration of aquatic habitats, the sustainable operation of reservoirs, or the management of particle-bound contaminant fluxes (Walling et al., 2003). These questions are generally facing a lack of data available at the watershed scale and at time scales from flood events to several years (Horowitz et al., 2015). The presence of dams significantly affects the SPM dynamics with large deposition in the reservoirs and possible resuspension during specific events when dam gates are opened. Sediment management in dam reservoirs and regulated rivers is indeed one important issue of the 21st century (Kondolf et al., 2014).

The development of station networks measuring SPM and particulate contaminants at large catchment scales remains limited due to the water sampling constraints and the cost of analyses (Horowitz, 2008). Data on SPM concentration $\left(C_{\mathrm{SPM}}\right)$ are mostly derived from discrete water sampling carried out as part of water quality monitoring programs (Walling and Webb, 1985; Phillips et al., 1999; Horowitz et al., 2001). The frequency of these measurements, generally performed with a fixed periodicity, is almost never high enough to measure the fine temporal variations in $C_{\mathrm{SPM}}$, leading to large uncertainties in flux budget estimation (Moatar et al., 2008). In recent decades, the development of surrogate techniques (Gray and Gartner, 2010) such as Optical Backscatter Systems (OBS, also known as turbidity meters) has allowed the continuous measurement of the SPM concentration, provided that sufficient calibration data are available 
(Foster et al., 1992; Gippel, 1995; Clifford et al., 1995; Thollet et al., 2013; Druine et al., 2018). Hydro-sedimentary stations based on water sampling and/or turbidity measurements at one point of the cross-section rely on the assumption of homogeneous SPM concentration (Horowitz, 2008). Nevertheless, the direct measurement of $C_{\mathrm{SPM}}$ at the river basin scale remains very expensive, time consuming and in many instances problematic, especially in inaccessible sections and during floods (Ulke et al., 2017). Most of the time, field data are available only for a particular event or over a limited period of time (Mano et al., 2008; Navratil et al., 2012).

Together with the deployment of denser measuring networks, hydro-sedimentary modelling allows the development of operational tools to improve the knowledge of the fate of suspended sediment in the river network (Wu et al., 2004). Moreover, it allows testing alternative management scenarios and several hypotheses on the water and SPM inputs. The use of numerical hydro-sedimentary models has increased considerably in the last decades in conjunction with the advances in computational techniques. One-dimensional (1-D) codes are admitted to be suitable for simulation over large temporal and spatial scales as they require less field data and computational resources than 2-D and 3-D codes do. The limited ability of $1-\mathrm{D}$ codes to reproduce fine physical processes is compensated by the stability of their numerical schemes and their fast calculation speed (Papanicolaou et al., 2008; El Kadi Abderrezzak and Paquier, 2009). Numerous 1-D codes have been developed and are frequently used for engineering purposes. Amongst others, Wu et al. (2004) and Papanicolaou et al. (2008) listed several 1-D codes and their applications to rivers and dam reservoirs. These codes can be classified according to their range of application or their formulations: steady/unsteady flow, fully coupled/semi-coupled/decoupled flow and suspended sediment modelling, uniform/non-uniform grain size, equilibrium/nonequilibrium suspended sediment transport model. 1-D modelling is particularly suitable for calculating SPM dynamics since SPM concentrations are generally assumed to be homogeneously distributed throughout a river cross-section and modelling transverse mixing is not necessary (Garneau et al., 2015). Modelling 
a flood event at the river basin scale requires i) calibrating the hydraulic and suspended sediment transport parameters, ii) specifying the water and SPM inputs (upstream boundary conditions) and iii) validating the results along the river system, including at the outlet.

The objective of this paper is to explore the use of a 1-D numerical model to better understand the spatial and temporal dynamics of SPM during floods throughout complex river networks. In particular, we test the application of a 1-D numerical model in simulating the SPM dynamics in a river regulated by a series of run-of-the-river dams and other infrastructure. There is indeed very limited feedback in the literature on the following questions. What kind of results is a 1-D model able to provide and what is the added value compared to observational data? What are the most sensitive parameters, hence the main sources of error? What are the most restrictive assumptions and the main perspectives for improvement?

The first part of the paper describes the May-June 2008 flood event in the Lower Rhône River. This hydro-sedimentary event was selected for testing the model as it was a typical combination of floods and dam flushing operations and it comes with a complete set of high temporal resolution measurements on the main tributaries and at the outlet. The second part of the paper presents the hydro-sedimentary numerical tools and the Rhône 1-D model used to simulate the May-June 2008 event. The Rhône 1-D model was developed as part of the Rhône Sediment Observatory (OSR) to become an efficient tool for managing SPM at the scale of the river basin. The third part details the results of the modelling and highlights the impacts of grain size distribution and hydropower structures on the simulated SPM concentrations and deposits. The main lessons learnt from the modelling exercise are briefly discussed and summarised in conclusive comments. 


\section{Case study}

\subsection{The Rhône River}

The Rhône River flows $810 \mathrm{~km}$ from its source in the Swiss Alps to its outlet to the Mediterranean Sea in the South of France (Fig. 1). It is the largest single source of freshwater to the Mediterranean Sea (Ludwig et al., 2009). Its hydrological regime is influenced by snow melting in headwater catchments, and by oceanic and Mediterranean rain events (Pardé, 1925). The three tributaries with the largest mean discharges are the Saône, Isère and Durance Rivers (Tab. 1). The Rhône River basin is characterized by a large geological and climatic heterogeneity, and by a dense network of hydropower schemes. From Lake Geneva to the Mediterranean Sea, the Rhône River is equipped with 21 hydropower schemes, all of which are run-of-the-river schemes except Génissiat Dam in the Upper French Rhône River (Fig. 1).

The Bourg-lès-Valence scheme detailed in Fig. 1 is typical of the other run-ofthe-river, by-passing hydropower plants (cf. Camenen et al. (2019) for a detailed description and analysis of sand fluxes). The Roche-de-Glun dam controls the discharge distribution between the Old Rhône and the power canal containing the Bourg-lès-Valence hydropower plant. A minimum compensation discharge is maintained in the Old Rhône at any time. During floods, when discharge exceeds the canal capacity, the excess flow is released in the Old Rhône. The particularity of this scheme lies in the confluence between the Isère River and the canal. In case of flood of the Isère River, the so-called Isère dam located between the headrace canal and the Old Rhône (cf. Fig. 1) can derive the excess discharge into the Old Rhône.

The Rhône River delivers substantial amounts of SPM to the Mediterranean Sea (Radakovitch et al., 2008; Launay, 2014) with a mean inter-annual SPM flux varying between 4.7 and 7.4 Mt/yr (Pont et al., 2002; Eyrolle et al., 2012; Ollivier et al., 2010; Launay, 2014; Copard et al., 2018; Poulier et al., 2019) but with huge variations of the annual SPM flux from one year to another. For example, annual SPM flux ranged from 1.2 to $22.7 \mathrm{Mt} / \mathrm{yr}$ between 1992 and 


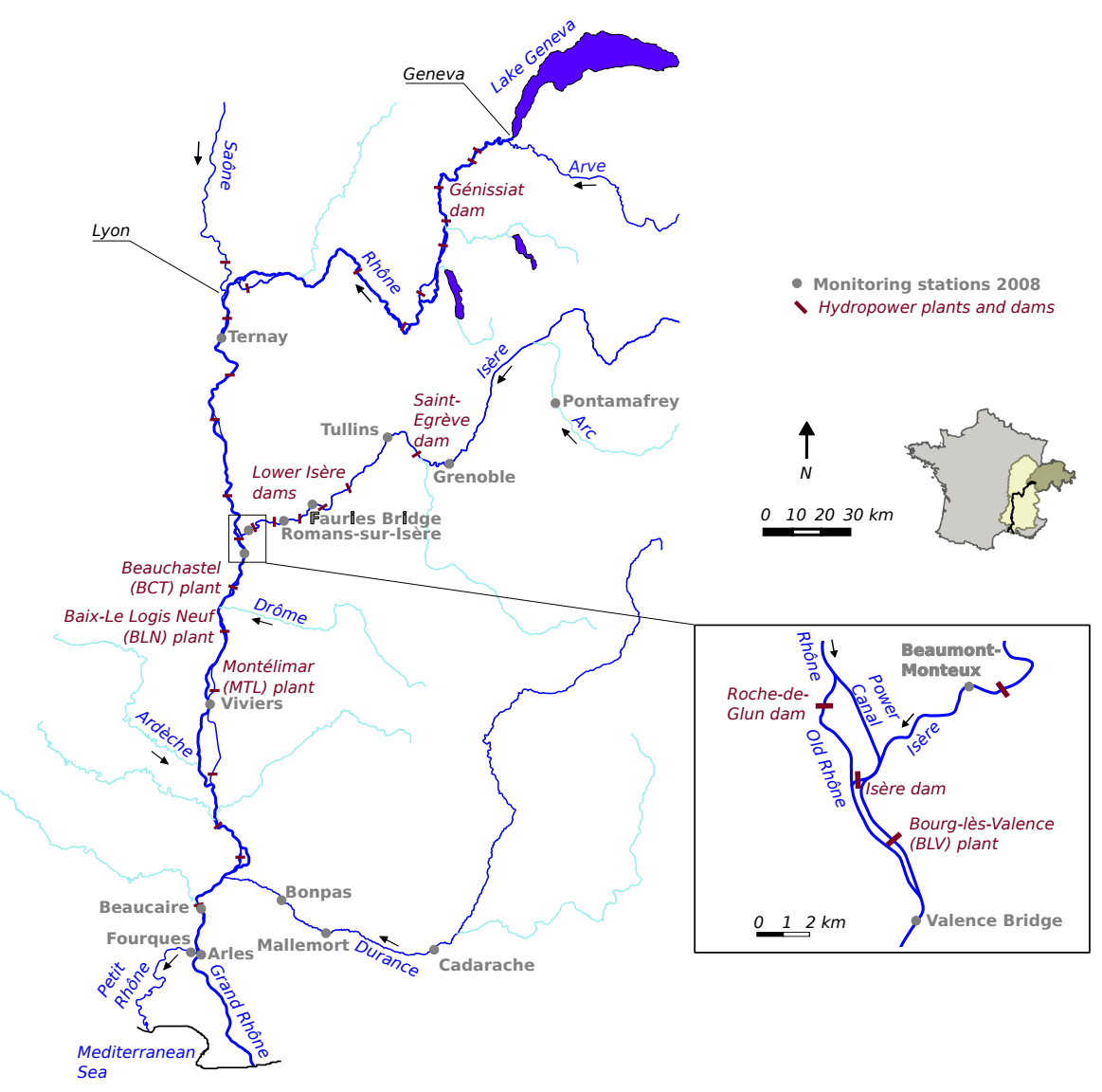

Figure 1: River network and hydroelectric schemes of the Rhône River from Lake Geneva to the Mediterranean Sea with a close-up view of the Bourg-lès-Valence hydroelectric scheme at the Rhône-Isère confluence. Monitoring stations of the May-June 2008 flood event in the Rhône, Arc, Isère and Durance Rivers are displayed.

1995 (Pont, 1997). Based on the long-term monitoring of $C_{\mathrm{SPM}}$ at Arles near the delta of the Rhône River, Eyrolle et al. (2012) showed that singular events (flood or dam flushing) can represent up to $95 \%$ of the annual SPM budget. The need for a better monitoring of SPM fluxes through the Rhône River motivated the creation of the Rhône Sediment Observatory (OSR) in 2009. As part of the OSR, an SPM monitoring network in the Rhône River and its tributaries from Lake Geneva to the Mediterranean Sea was developed mostly based on turbidity measurements calibrated with frequent SPM samples. 
Table 1: General information on the catchments and hydrological regimes of the Rhône River and its main tributaries.

\begin{tabular}{lrrrrrr}
\hline Station & $\begin{array}{r}A \\
{\left[\mathrm{~km}^{2}\right]}\end{array}$ & $\begin{array}{r}Q_{a} \\
{\left[\mathrm{~m}^{3} / \mathrm{s}\right]}\end{array}$ & $\begin{array}{r}F_{a} \\
{[\mathrm{Mt} / \mathrm{yr}]}\end{array}$ & $\begin{array}{r}Q_{\max , 2003} \\
{\left[\mathrm{~m}^{3} / \mathrm{s}\right]}\end{array}$ & $\begin{array}{r}Q_{\max , 2008} \\
{\left[\mathrm{~m}^{3} / \mathrm{s}\right]}\end{array}$ & $\begin{array}{r}C_{\max , 2008} \\
{[\mathrm{~g} / \mathrm{L}]}\end{array}$ \\
\hline Rhône at Lyon & 20300 & 600 & 0.6 & 813 & 1206 & - \\
Saône at Lyon & 29908 & 475 & 0.4 & 1262 & 568 & - \\
Isère at Beaumont & 11890 & 333 & 2.3 & 1513 & 1458 & 25.2 \\
Durance at Bonpas & 14225 & 190 & 1.7 & 1496 & 1495 & 11.1 \\
Rhône at Beaucaire & 95590 & 1690 & $4.7-6.7$ & 11500 & 5126 & 5.0 \\
\hline
\end{tabular}

$A=$ catchment area, $Q_{a}=$ mean annual discharge, $F_{a}=$ mean annual SPM flux according to Launay (2014), $Q_{\max , 2003}$ and $Q_{\max , 2008}=$ maximum discharges for the events of December 2003 and May-June 2008, $C_{\max , 2008}=$ maximum $C_{\mathrm{SPM}}$ for the May-June 2008 flood event.

According to Launay (2014) and Poulier et al. (2019), the main four tributaries in terms of SPM contribution to the Rhône River are the Arve River, the Saône River, the Isère River and the Durance River (Fig. 1 and Tab. 1). The SPM output of Lake Geneva is assumed to be negligible due to the large trapping capacity of the lake. The Isère and Durance Rivers are left bank alpine tributaries of the Rhône River with fast and violent floods. The main SPM contributor of the Isère River is the Arc River, a mountainous river producing fine SPM (Camenen et al., 2016). The six Lower Isère dams located between Grenoble and the Rhône confluence near Valence (Fig. 1) are run-of-the-river dams. Only the lowest Isère dam, Beaumont-Monteux, by-passes the Isère River with a derivation canal.

\subsection{The 2008 hydro-sedimentary flood event}

In May-June 2008, a major hydro-sedimentary event occurred in the Lower Rhône River, combining natural floods in its two main tributaries, the Isère 
and Durance Rivers, and flushing operations of the Lower Isère dams. All the reservoirs of the Lower Isère and the Lower Rhône are run-of-river dams with very limited storage capacity. They can be partially drained and sediment flushing operations must meet precise regulation requirements. Isère dams can be flushed during flood falling phases in order to evacuate excess deposited sediment. Rhône dams are not expected to be flushed but their operation can be adapted to avoid deposition in critical areas such as around navigation locks or dam gates. This could not be done during the 2008 event presented here due to a lack of understanding and forecasting of the hydro-sedimentary processes, and a lack of real-time coordination between the two distinct companies that operate the Isère dams and the Rhône dams, respectively.

The peak discharge recorded at the Beaucaire station during this event was $5125 \mathrm{~m}^{3} / \mathrm{s}$, corresponding to a 2-year return period flood. Between May 26th and June 8th 2008, the Arles station recorded a total SPM flux of $4.2 \mathrm{Mt}$ at the Rhône outlet (Eyrolle et al., 2012), equivalent to the SPM output of the 100-year flood in 2003 which had a twice larger peak discharge (Tab. 1). The May-June 2008 flood event in the Lower Rhône River was also remarkable because it produced an SPM flux almost equal to the mean annual SPM export of the Rhône River to the Mediterranean Sea recorded since 2005 (Launay, 2014).

During the 2008 flood event, SPM concentrations were measured at the monitoring stations presented in Fig. 1, either continuously using OBS or the acoustic attenuation method presented by Moore et al. (2012), or by samplingfiltration method (AFNOR, 2005). All the SPM samples were taken near the free-surface using buckets or automatic samplers. They include the homogeneously distributed suspension ("washload"), not the graded sand suspension. Well mixed cross-sections were chosen for the monitoring of $C_{\mathrm{SPM}}$ except for the Rhône station at Valence Bridge, where the Isère and Rhône waters were not fully mixed. Available SPM data cover the Arc-Isère-Rhône river network, the Rhône-Isère confluence with numerous samples, the Durance River network, and some stations along the Rhône River.

Fig. 2 presents the water discharge times series and $C_{\mathrm{SPM}}$ data collected 
during the event at the outlet of the Arc, Isère and Durance Rivers, and at four stations of the Rhône River. The Rhône at Ternay station is located upstream of the Isère confluence and monitors the discharge and SPM inputs from the Upper Rhône River. The Rhône at Viviers station provides an intermediate checkpoint to study the Isère River input independently from the Durance input. This is the first monitoring station downstream of the Isère confluence with a complete $C_{\text {SPM }}$ time series for the May-June 2008 flood event, while the Rhône at Valence station recorded $C_{\mathrm{SPM}}$ only during the third period of the event. The Beaucaire station located near the outlet of the Rhône River gives indication on the SPM fluxes delivered to the Mediterranean Sea. The Beaucaire station is the last discharge monitoring station for the Rhône River before the separation of the two branches of the Rhône Delta. The measurement of $C_{\mathrm{SPM}}$ is performed at the Arles station located about $13 \mathrm{~km}$ downstream on the Grand Rhône branch. The SPM concentrations are considered to be the same at Beaucaire and Arles for the SPM flux calculation.

The measured SPM fluxes were determined by multiplying the instantaneous water discharges and the instantaneous $C_{\mathrm{SPM}}$. For monitoring stations with occasional $C_{\mathrm{SPM}}$ measurements (samples), the SPM fluxes were estimated by establishing a power relation between discharge and $C_{\mathrm{SPM}}$ to reconstruct a continuous $C_{\mathrm{SPM}}$ time series.

The event can be divided into three SPM-producing periods (Fig. 2). The first period covers the dam flushing of the Saint-Egrève dam occurring between 26/05/2008 and 29/05/2008 in the Isère River. This dam flushing was triggered concomitantly with a 1-year return period flood of the Isère River, with discharges up to $1000 \mathrm{~m}^{3} / \mathrm{s}$ at the Beaumont-Monteux station. During this period, the Lower Isère dams were operated with high water levels in the reservoirs, and the water overflowing the gates. Meanwhile, a substantial flood occurred in the Durance River, with $C_{\mathrm{SPM}}$ greater than $10 \mathrm{~g} / \mathrm{L}$ on the $27 / 05 / 2008$. The management of the hydropower schemes of the Durance River during this period led to mitigate the discharge (around $800 \mathrm{~m}^{3} / \mathrm{s}$ ) while releasing a large amount of SPM. To account for the flood wave time lag between the upstream 
part of the catchment and its downstream part, the ending date of the first period was postponed to the $30 / 05 / 2008$ for the downstream part. During the second period, from 29/05/2008 to 02/06/2008, a large flood of the Arc River was recorded with $C_{\mathrm{SPM}}$ greater than $30 \mathrm{~g} / \mathrm{L}$, causing a $C_{\mathrm{SPM}}$ peak greater than $20 \mathrm{~g} / \mathrm{L}$ in the Isère at Beaumont-Monteux on the 30/05/2008. This peak propagated in the Rhône River and about $8 \mathrm{~g} / \mathrm{L}$ were recorded at Viviers on the $31 / 05 / 2008$. During this period, the Lower Isère dams were not flushed, but the bottom gates were opened. The second period runs from 30/05/2008 to $03 / 06 / 2008$ to account for flood propagation delay. During this period, a major flood occurred in the Durance River with discharge up to $1500 \mathrm{~m}^{3} / \mathrm{s}$ and $C_{\text {SPM }}$ up to $6 \mathrm{~g} / \mathrm{L}$. The third period lasted from $02 / 06 / 2008$ to $10 / 06 / 2008$, for which the Lower Isère dams were flushed, with low water level in the reservoirs to evacuate the deposited sediments. The cloud of SPM was recorded around 04/06/2008 in the Isère at Beaumont-Monteux with maximum $C_{\mathrm{SPM}}$ around $20 \mathrm{~g} / \mathrm{L}$. It was recorded in the Rhône at Viviers with a propagation delay of one day and the peak $C_{\mathrm{SPM}}$ was about $2 \mathrm{~g} / \mathrm{L}$. 
Author-produced version of the article published in Launay, M., Dugué, V., Faure, J.-B., Coquery, M., Camenen, B., Le Coz, J. (2019)

Numerical modelling of the suspended particulate matter dynamics in a regulated river network, Science of the Total Environment, $665,591-605$, DOI : 10.1016/j.scitotenv.2019.02.015

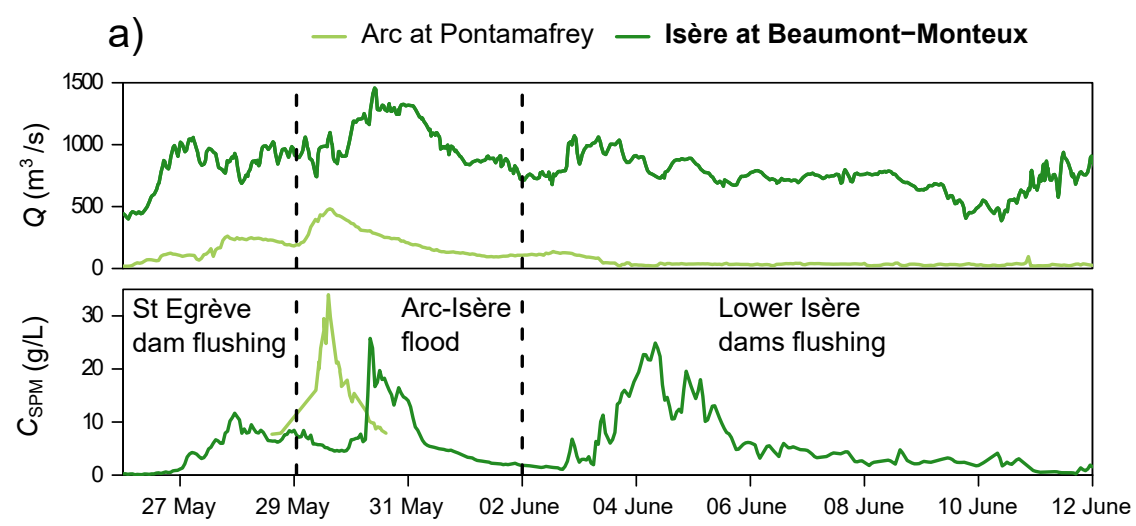

b)
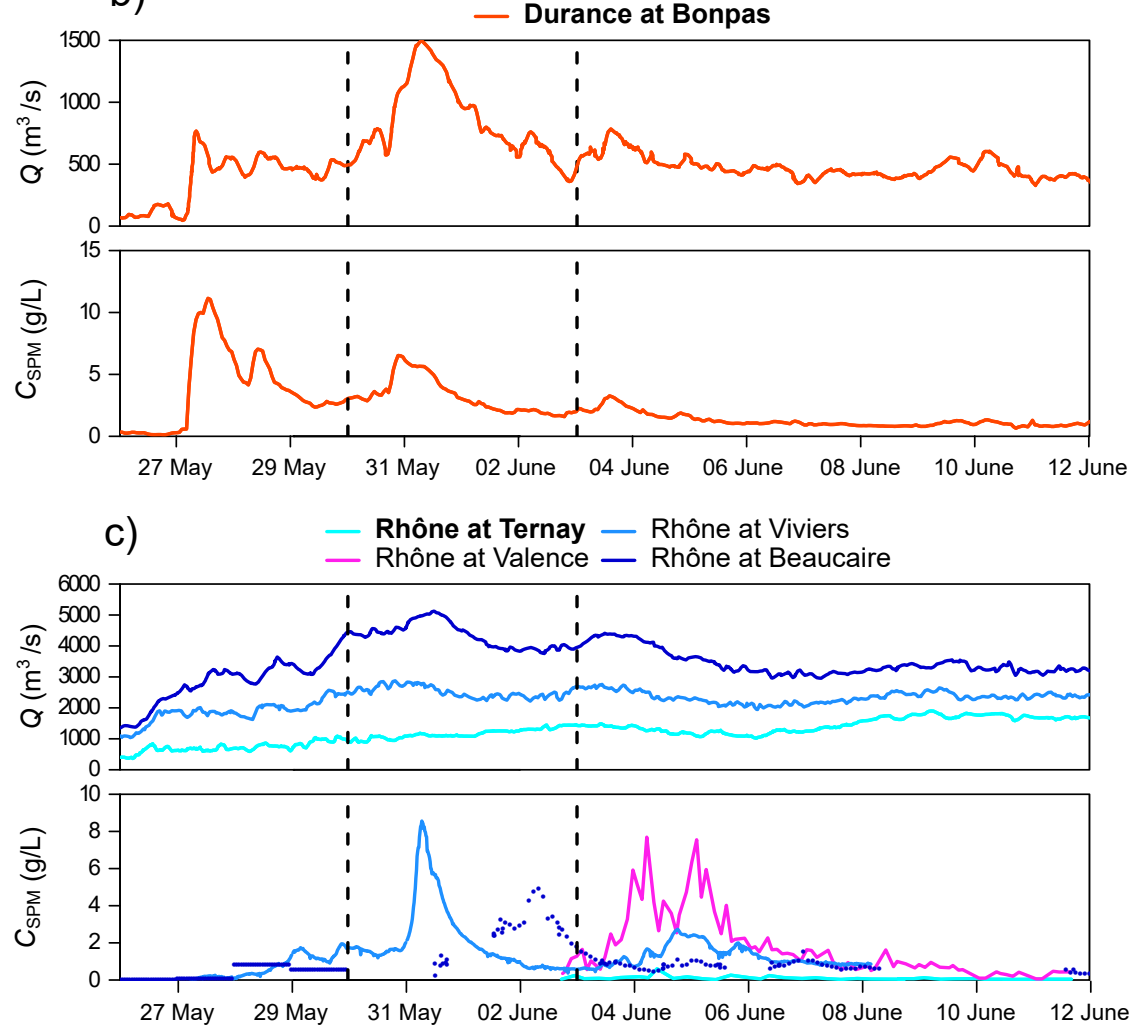

Figure 2: Discharges and SPM concentration $\left(C_{\mathrm{SPM}}\right)$ in $(\mathrm{a})$ the Arc and Isère Rivers, $(\mathrm{b})$ the Durance River and (c) the Rhône River during the May-June 2008 flood event. The limits of the three periods are shown with vertical dashed lines: on the 29/05/2008 and 02/06/2008 for the Isère River, on the 30/05/2008 and 03/06/2008 for the Durance River and the Lower Rhône River. Monitoring stations indicated in bold are the upstream boundary conditions of the model. 


\subsection{SPM inputs from the Isère River}

A $C_{\mathrm{SPM}}$ time series was reconstructed at the outlet of the Isère River since a continuous $C_{\text {SPM }}$ time series was not available at the Isère at BeaumontMonteux for the entire event (Fig. 3). The measurements used for the reconstruction were taken at Tullins (turbidimeter, Rieux, 2008), Romans-surIsère (side-looking hydroacoustic profiler, Moore et al., 2012), Beaumont-Monteux (manual water samples, Rieux, 2008) and the Rhône at Viviers. Between $26 / 05 / 08$ and $30 / 05 / 08$, the reconstructed $C_{\mathrm{SPM}}$ time series followed the measurements at Romans-sur-Isère, the closest station upstream of Beaumont-Monteux, with an estimated time lag of $1 \mathrm{~h}$. Time lag between stations was calculated based on $C_{\mathrm{SPM}}$ peaks. Similarly, between $01 / 06 / 08$ and $02 / 06 / 08$, the reconstructed $C_{\mathrm{SPM}}$ time series followed the measurements at Tullins with an estimated time lag of $10 \mathrm{~h}$. However data based on Tullins station may be underestimated if erosion occurs in the Lower Isère reservoirs. Between 30/05/08 and 01/06/08, those reservoirs were flushed; as no representative measurements were available, the SPM concentration at Beaumont-Monteux was evaluated as the SPM flux in the Rhône at Viviers divided by the water discharge of the Isère at Beaumont-Monteux. The rationale behind this computation is that during that period the SPM flux coming from the Rhône upstream of the Isère junction was negligible with respect to the SPM flux coming from the Isère. This approximation is reasonable as discharges and SPM concentrations remained very low in the Rhône upstream of the Isère junction during that period of time. Finally, from 03/06/2008 on, SPM concentrations were measured at BeaumontMonteux. 


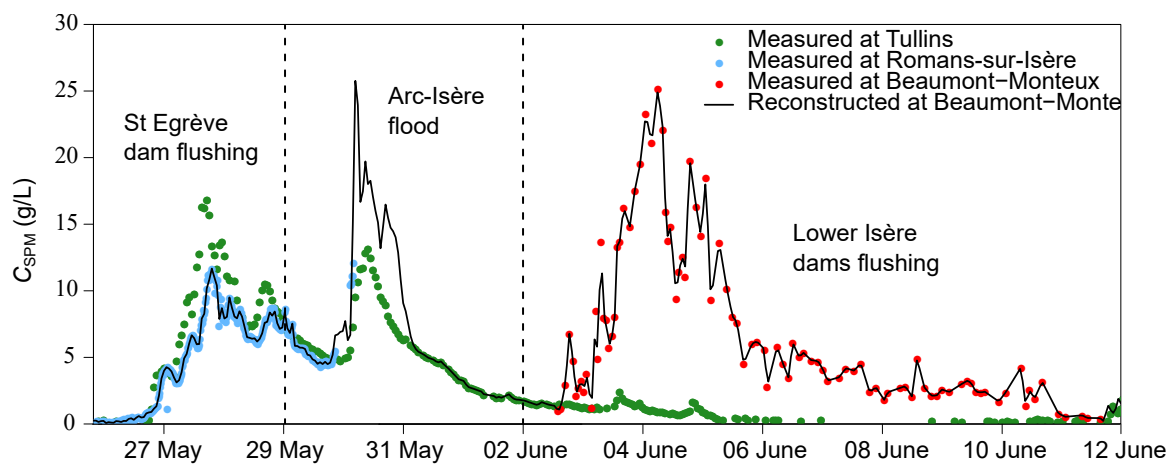

Figure 3: Reconstruction of the SPM concentration $\left(C_{\mathrm{SPM}}\right)$ time series of the Isère River at Beaumont-Monteux station from SPM measurements at Tullins and Romans-sur-Isère stations from $26 / 05 / 2008$ to $12 / 06 / 2008$.

\section{1-D modelling of the May-June 2008 flood event}

\subsection{Numerical codes}

The 1-D hydro-sedimentary numerical tool used in this study was developed by Irstea. It couples the Mage and AdisTS hydro-sedimentary numerical codes. Mage (Souhar and Faure, 2009) is a 1-D hydrodynamic code which simulates transient open-channel flows by solving the 1-D Barré de Saint-Venant equations (shallow water equations):

$$
\frac{\partial A_{w}}{\partial t}+\frac{\partial Q}{\partial x}=q_{l a t}
$$

$$
\frac{\partial Q}{\partial t}+\frac{\partial}{\partial x}\left(\beta \frac{Q^{2}}{A_{w}}\right)+g A_{w} \frac{\partial z}{\partial x}=-g S\left(J+J_{s}\right)+k q_{l a t} V
$$

where $A_{w}$ is the wetted area, $Q$ the water discharge, $t$ the time, $x$ the longitudinal coordinate, $q_{\text {lat }}$ a lateral input/output discharge, $\beta$ the momentum coefficient, $z$ the water surface elevation, $J$ the energy slope computed using the Manning-Strickler equation, $J_{s}$ the local energy losses due to sharp variation of the cross-section, $k$ a coefficient depending on the sign of $q_{l a t}(k=1$ if $q_{\text {lat }}<0, k=0$ if $q_{\text {lat }} \geq 0$ ), and $V=Q / A_{w}$ the cross-section-averaged velocity.

Mage describes the real geometry of the river bed as a series of cross-sections, and accounts for compound channel effects using the Debord equations (Nicollet 
and Uan, 1979). Storage nodes can be defined to model floodplain areas where the water velocity may be assumed to be negligible. No storage nodes were used in the presented simulations. The river network topology may be looped (bifurcations, confluences), with multiple downstream boundary conditions. The 1-D Barré de Saint-Venant equations are solved using a four point semi-implicit finite-difference scheme (Preissmann scheme).

AdisTS (Guertault et al., 2016) is a 1-D code solving mass conservation equations for SPM transport in parallel. The code includes advection-dispersion equations in conservative formulation (Eq. 3) for several SPM classes. SPM grain size distribution (GSD) is reproduced by mixing a fixed number of classes of different proportion. The equations are coupled using source terms that allow modelling erosion and deposition terms:

$$
\frac{\partial A_{w} C_{i}}{\partial t}+\frac{\partial Q C_{i}}{\partial x}-\frac{\partial}{\partial x}\left(D_{f} A_{w} \frac{\partial C_{i}}{\partial x}\right)=\left(E_{i}-D_{i}\right) W_{z}
$$

where $C_{i}$ is the concentration in SPM class $i, E_{i}$ and $D_{i}$ are erosion and deposition fluxes of SPM class $i, D_{f}$ is the longitudinal diffusion coefficient, and $W_{z}$ is the river width. The source term combines the Partheniades (1965) formula for erosion and the Krone (1962) formula for deposition:

$$
E_{i}-D_{i}=a_{\mathrm{PD}, i}\left(C_{\mathrm{eq}, i}-C_{i}\right) w_{s, i}
$$

where $C_{\mathrm{eq}, i}$ is the equilibrium concentration for the SPM class $i, a_{\mathrm{PD}, i}$ is a recovery coefficient, reflecting non equilibrium sediment transport (Han, 1980; Armanini and Di Silvio, 1988), and $w_{s, i}$ is the settling velocity of the SPM class $i$. The equilibrium concentration depends on the effective bed shear stress, $\tau_{\text {eff }}$ as:

$$
C_{\mathrm{eq}, i}= \begin{cases}C_{0, i}\left(\frac{\tau_{\mathrm{eff}}}{\tau_{\mathrm{cr}, i}}-1\right) & \text { if } \frac{\tau_{\mathrm{eff}}}{\tau_{\mathrm{cr}, \mathrm{i}}}>1 \\ 0 & \text { otherwise }\end{cases}
$$

where $C_{0, i}$ is a calibration concentration specific to SPM class $i, \tau_{\mathrm{cr}, i}$ is the critical shear stress for initiation of movement of SPM class $i$, estimated using the Shields diagram. For fine sediments $(d<70 \mu \mathrm{m})$, since consolidation can be neglected when simulation is performed at event scale, the critical bed shear 
stress is assumed independent of the grain size for fine sediments $\left(\tau_{\mathrm{cr}}=0.15 \mathrm{~Pa}\right)$. The effective bed shear stress is computed as $\tau_{\text {eff }}=\left(K_{S} / K_{S}^{\prime}\right) \tau$, with $K_{S}$ the total Strickler coefficient, $K_{S}^{\prime}=24 / d_{90}^{1 / 6}$ the skin-friction Strickler coefficient. The total bed shear stress $\tau=\rho g R_{h} J$ is computed using the 1-D hydraulic model ( $\rho$ water density and $R_{h}$ hydraulic radius). The calibration of the two AdisTS parameters, $a_{\mathrm{PD}, i}$ and $C_{0, i}$, was performed as functions of the grain size by Guertault et al. (2016) on Génissiat hydropower scheme in the Rhône River.

The longitudinal diffusion coefficient $D_{f}$ was calculated using the formula of Iwasa and Aya (1991) as Launay et al. (2015) concluded it was the best suited based on their analysis of tracing experiments and hydro-acoustic measurements in the Rhône River near Lyon.

AdisTS is loosely coupled with Mage software. The bed geometry remains fixed over time but the model simulates a potential stock of sediments available over each channel (main channel and floodway) in each cross-section. This stock is spatially distributed using a mean thickness and assuming a constant porosity $p=0.45$; it can vary in mass and GSD over time due to erosion and deposition. Indeed, the advection-dispersion equation is solved for each sediment class and the GSD of bed sediment stocks depend on the erosion or deposition simulated along the system for each class independently. It is possible to specify initial sediment stocks along the river system but for the presented simulations no initial stock was assumed. Over long timescales, there may be geometric feedbacks that change channel capacity when erosion and sedimentation do not balance. However, the fixed-bed assumption has limited consequences over the timescale of an individual event. It allows a faster calculation which is of particular interest when dealing with long river reaches and long-term scenarios with limited bed evolution.

The 1-D numerical tool can be used to identify the origin of the water flowing at a downstream monitoring station. This identification is done by injecting a numerical tracer in each tributary $j$ with concentration $C_{j, \text { ref }}=1 \mathrm{~g} / \mathrm{L}$. At a downstream monitoring station where the total water discharge $Q$ is calculated, the proportion of water $Q_{j} / Q$ coming from the tributary $j$ can be determined 
based on the tracer mass continuity equation: $Q_{j} / Q=C_{j} / C_{j, \text { ref }}$, where $C_{j}$ is the concentration of tracer coming from the tributary $j$ calculated at the station. Similarly, each SPM class $i$ from each tributary $j$ can be traced so that concentration $C_{\mathrm{SPM}, i, j}$ is computed at each node and at each time of the simulation.

\subsection{1-D model of the Rhône River}

The Rhône 1-D model, developed by Irstea as part of the OSR program, represents the Rhône River from Lake Geneva to the Mediterranean Sea (Fig. 1). Bathymetry surveys of the river cross-sections are available every $500 \mathrm{~m}$ streamwise. Lidar data were used to complete some profiles in the main channel and to estimate the extent of the floodway. Additional profiles were included to represent dams and hydroelectric plants. In the model, cross-sectional profiles were interpolated every $100 \mathrm{~m}$. Cross-sections of the major tributaries (Arve, Ain, Saône, Isère and Durance Rivers) were also included to represent their lowest sections up to their confluences with the Rhône River. Other tributaries are only represented as local inputs.

Flow resistance coefficients of the main channel $\left(30 \leq K_{S} \leq 42 \mathrm{~m}^{1 / 3} / \mathrm{s}\right)$ were calibrated and validated over each reach using longitudinal water profiles measured over a wide range of discharges from low water to flood conditions $\left(1500 \leq Q \leq 4500 \mathrm{~m}^{3} / \mathrm{s}\right)$. It was not necessary to vary the flow resistance coefficients with discharge to achieve an acceptable calibration, i.e. stage errors lower than $0.1 \mathrm{~m}$, typically. Flow resistance coefficients of the floodways (over bars, islands, etc.) were assumed to be equal to $20 \mathrm{~m}^{1 / 3} / \mathrm{s}$ everywhere. The floodways of the Rhône River are narrow due to the presence of dykes and overbank flows are limited. Therefore, the results are not much sensitive to the values of the flow resistance coefficient defined for the floodways. The model does not include floodplains and cannot be used to simulate flooding over dikes.

The model includes the operation rules of the 21 run-of-the-river hydropower schemes (Dugué et al., 2015). All the Rhône dams included in the model have a bypass channel (remember that no Isère dams are included in the computa- 
tional domain). The operation rules of the run-of-the-river hydropower schemes impose a minimum compensation discharge in the bypassed channel and a maximum discharge in the power canal as allowed by the hydropower plant (Dugué et al., 2015). Also, the maximum water level at a regulation point in each reservoir is prescribed through legal dam operation rules which the operator has to follow, especially during floods, whatever the initial storage is. Such run-ofriver dams actually have a limited storage capacity and the water level in the reservoir can be regulated by opening the dam gates, typically. The legal dam operation rules are specific to each dam and relate the maximum allowed water level as a function of inflow, usually.

For the specific study of the May-June 2008 flood event, the 1-D numerical model was restricted to the Lower Rhône River, starting from Ternay station. Eleven hydropower schemes are present in the study area. In this configuration, the model has three main upstream boundary conditions: the Rhône at Ternay, the Isère at Beaumont-Monteux (i.e. just downstream of the last dam of the Lower-Isère chain of dams) and the Durance at Bonpas (see Fig. 1). The smaller tributaries located between Ternay and the Mediterranean Sea are considered as local water inputs. Both discharge and $C_{\mathrm{SPM}}$ time series for the three main upstream boundaries are indicated as thick lines in Fig. 2. The discharge of the smaller tributaries were also simulated. The downstream boundary conditions on the Rhône Delta are the water levels measured in the Grand Rhône branch and in the Petit Rhône branch (cf. Fig. 1).

Upstream of the Isère confluence, the SPM concentration in the Rhône River at Ternay was lower than $0.2 \mathrm{~g} / \mathrm{L}$ typically (cf. Fig. 2c), which is much lower than the SPM concentration of the Isère and Durance tributaries during the flood event. As the discharge time series at Ternay does not indicate any flood, the SPM input at Ternay was set to zero for the simulations. The $C_{\mathrm{SPM}}$ time series used as input for the Isère River at Beaumont-Monteux was reconstructed as discussed in section 2.3. For the Durance River, SPM time series was recorded at Bonpas turbidity station (Fig. 2b). SPM inputs from smaller tributaries were considered to be negligible during the May-June 2008 flood event compared to 
the inputs of the Isère and Durance Rivers.

\subsection{Grain size distributions}

The 1-D numerical model requires information on the grain size distribution (GSD) of the SPM. Numerical simulations on the Rhône River were performed using six SPM classes with variable grain sizes from clay to medium sand, and assuming grain size distribution of each class to be log-normal of parameters $d_{50, i}$ and $\sigma_{i}$ (see Tab 2). $d_{50, i}$ and $\sigma_{i}$ are assumed constant in time; only the relative proportion of the class $i$ (in the total SPM concentrations and stocks) may vary in time.

The three classes with the finest SPM were determined based on grain size analysis of Rhône SPM samples (Launay, 2014) and the three classes with the coarsest SPM were defined by Guertault (2015). These classes were defined so as to best represent main groups of particles that systematically show up in the measured grain size distributions. Eventually, only the first four finest classes will be used for this study, the two coarsest sand classes being easily trapped by dam reservoirs (Camenen et al., 2019). The representative settling velocity $w_{s, i}$ for each class of sediment $i$ was calculated using Camenen (2007) formula and assuming the grain size distribution of each class to be log-normal (cf. Tab. 2). Cohesion is neglected since organic content is very low $(<5 \%$, typically) as well as cohesiveness (Legout et al., 2018). The impact on settling velocity (flocculation) is thus relatively low, and there is actually no possible validation of any flocculation model for this specific case.

No GSD was measured in the Isère or Durance Rivers during the May-June 2008 flood event. Grain size analysis of the SPM of the Isère River in 2008 and during a similar hydrological event in 2015 showed that the particles of the Isère River and the SPM collected in the Rhône River during the 2012 dam flushes have similar grain size distributions. Therefore, the parameters calibrated by Guertault et al. (2016) were kept to simulate the 2008 flood event. The same assumption was made on Durance SPM although no grain size analysis was performed on SPM samples of the Durance River. 
Table 2: Physical properties of the elementary SPM classes and AdisTS coefficients $a_{P D, i}$ and $C_{0, i}$, as proposed by Guertault (2015). Proportions of the SPM classes in the three SPM mixtures tested with the numerical model for the Isère input.

\begin{tabular}{lcccccc}
\hline Name & Class 1 & Class 2 & Class 3 & Class 4 & Class 5 & Class 6 \\
\hline Median diameter: $d_{50, i}(\mu \mathrm{m})$ & 4 & 15 & 45 & 90 & 200 & 400 \\
Standard deviation of $\ln \left(d_{i}\right): \sigma_{i}(-)$ & 0.32 & 0.24 & 0.17 & 0.17 & 0.20 & 0.20 \\
Settling velocity: $w_{s, i}(\mathrm{~m} / \mathrm{s})$ & $2.810^{-5}$ & $2.310^{-4}$ & $1.410^{-3}$ & $7.510^{-3}$ & $2.610^{-2}$ & $5.810^{-2}$ \\
Critical shear stress: $\tau_{\mathrm{cr}, i}(\mathrm{~Pa})$ & 0.153 & 0.154 & 0.155 & 0.158 & 0.174 & 0.232 \\
Recovery coefficient: $a_{\mathrm{PD}, i}$ & 1 & 1 & 1 & 1 & 1 & 1 \\
Calibration concentration: $C_{0, i}(\mathrm{~g} / \mathrm{L})$ & 1 & 1 & 0.5 & 0.2 & 0.2 & 0.2 \\
\hline$\%$ in Mixture A - Fine & 31 & 44 & 25 & 0 & 0 & 0 \\
\% in Mixture B - Medium & 23 & 28 & 31 & 18 & 0 & 0 \\
$\%$ in Mixture C - Coarse & 12 & 18 & 40 & 30 & 0 & 0 \\
\hline
\end{tabular}

Samples collected in other occasions in the Arc-Isère network were used to determine three possible GSD for the SPM transported by the Isère River in May-June 2008, named Mixtures A, B and C (see Fig. 4 and Tab. 2). The measured GSD were approximated using a mixture of log-normal distributions, as explained by Masson et al. (2018).

Two surface water samples were collected during floods of the Arc River (June 2015, documented by Camenen et al. (2016)) and the Isère River (May 2015). The Arc River is the main natural SPM input to the Isère River. The SPM usually transported by the Arc River represent the finest SPM transported during a flood in the Arc-Isère river network (classes 1 and 2 composed of clay and fine silt). They were averaged to give Mixture A - Fine GSD (Fig. 4). Two samples of riverbed sediment were collected in the Rhône River after the May-June 2008 flood event. One sample was collected downstream of the Bourglès-Valence (BLV) plant (06/08/2008), and the other sample was collected in the garage of the BLV lock (23/06/2008). Additionally, one sample was taken after the flood of May 2015 from a deposit near the right bank of the Isère River downstream of Beaumont-Monteux. Bank deposit and riverbed sediment 
samples correspond to the coarsest SPM transported during a flood. They were averaged to compose Mixture C - Coarse GSD, which is considered as an extreme scenario for which most of the SPM would be made of that coarsest fraction. Finally, one sample taken in the water column close to the bottom at the Rhône and Isère confluence during the May 2015 flood contained particles from clay to coarse silt in equal proportions. This intermediate sample constitutes Mixture B - Medium GSD.

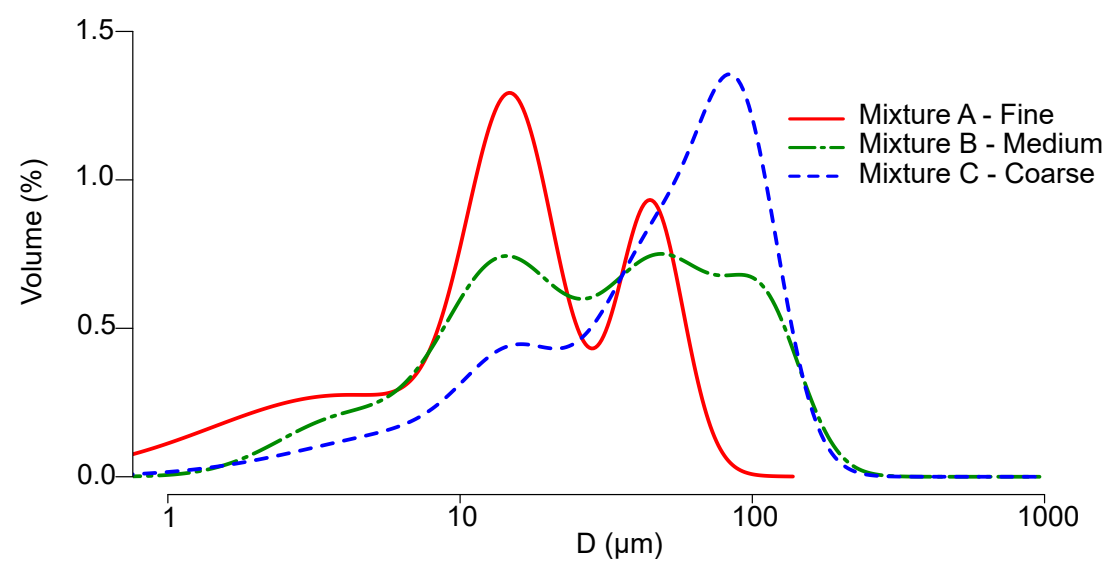

Figure 4: Three possible grain size distributions for the SPM transported by the Isère River during the May-June 2008 flood event.

The SPM of the Durance River was assumed to be composed of clay only (class 1), with a median diameter $d_{50}$ of $4 \mu \mathrm{m}$. This hypothesis relies only on field observation of the very fine aspect of the washload transported by the Durance River.

\section{Results}

4.1. Origin of water discharge during the May-June 2008 flood event

The contributions of the Isère and Durance Rivers to the Rhône River water discharge during the May-June 2008 event were evaluated using the 1-D model. The hydrograph decomposition results are presented for the Rhône at Valence 
Bridge, Viviers and Beaucaire stations (Fig. 5). Overall, the simulated discharge is within $10 \%$ of the measured discharge, except for short transient phases. This is less than the expected level of uncertainty of hourly discharge measurements (Horner et al., 2018), which suggests that the main sources of water and their propagation through the river network are correctly simulated by the model.
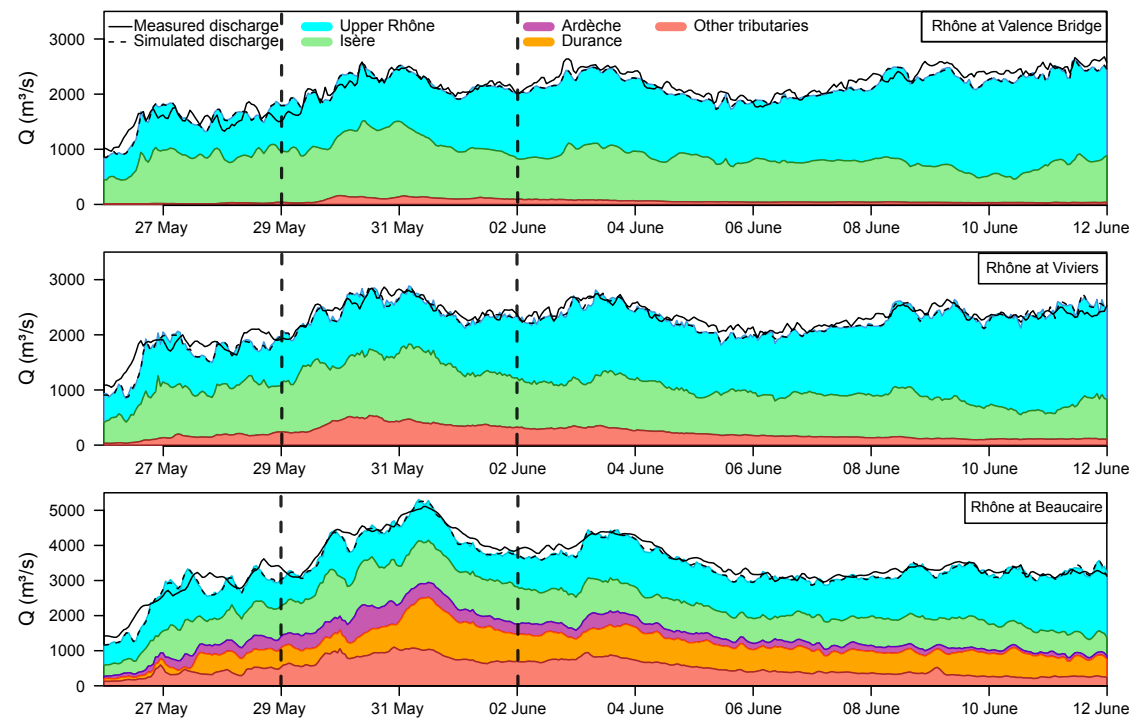

Figure 5: Decomposition of the flow hydrographs of the May-June 2008 flood event at the hydrometric stations of the Rhône at Valence, Viviers and Beaucaire using the 1-D hydrodynamic model. The three periods (see section 2.2) are separated by the vertical dashed lines.

At Valence Bridge station (Fig. 5a), two water sources can be distinguished: the Upper Rhône River (upstream of Ternay) and the Isère River. The contribution of the tributaries between Ternay and Valence was very small during the event. The Upper Rhône River was not in flood during the period of the MayJune 2008 flood event, so the shape of the hydrograph at Valence Bridge was mainly influenced by the Isère River contribution. At Viviers station (Fig. 5b), the contribution of the tributaries other than the Isère is increased by water inputs from the Eyrieux, Drôme, Right-bank Ouvèze and Roubion Rivers. The 
discharge contribution of these tributaries is higher than that of previous tributaries between Ternay and Valence but remains small. At Beaucaire (Fig. 5c), most of the water came from the Upper Rhône (from 20 to 40 \%), the Isère (around $25 \%$ )and the Durance (around $25 \%$ ) Rivers, with smaller inputs from the Ardèche and other tributaries.

\subsection{Impact of grain size distribution on simulated SPM concentrations}

During the May-June 2008 flood event, one can expect different sources of SPM for the three distinct periods described in section 2.2, with dam flushing operation during the 1st and the 3rd periods and natural floods during the 2nd period. As a consequence, one can expect different GSD for each of these periods. As the GSD of SPM transported by the Isère River were not measured in 2008 , simulation tests were run using the three hypothetical mixtures defined in Tab. 2 from samples collected in the Isère River during other events (Section 3.3). Results from these three simulations are presented in Fig. 6.

Simulated concentrations $C_{\mathrm{SPM}}$ obtained at Viviers station are compared with measured concentrations in Fig. 6. Simulated SPM concentrations are sensitive to grain size due to erosion/deposition and transport processes. Concentrations $C_{\mathrm{SPM}}$ at Viviers using the coarse GSD (Mixture C) are half the $C_{\text {SPM }}$ simulated using the fine GSD (Mixture A). This is explained by the more intense deposition of the coarsest particles within the four hydropower schemes between the lowest Isère dam and Viviers.

For the flood period, although concentrations at Beaumont-Monteux were evaluated based on Viviers concentrations, the model yields an underestimation of the peak concentrations whatever the choice of GSD. This results from dispersion processes. The concentration peak at Beaumont-Monteux should thus have been higher and narrower to take into account this effect. The difference between measured and simulated $C_{\mathrm{SPM}}$ could also be partly due to an overestimation of the $C_{\mathrm{SPM}}$ measured at Viviers by the acoustic attenuation method, particularly when fine particles are highly concentrated, which increases the acoustic attenuation (Moore et al., 2013). 
Author-produced version of the article published in Launay, M., Dugué, V., Faure, J.-B., Coquery, M., Camenen, B., Le Coz, J. (2019)

Numerical modelling of the suspended particulate matter dynamics in a regulated river network, Science of the Total Environment, $665,591-605$, DOI : 10.1016/j.scitotenv.2019.02.015
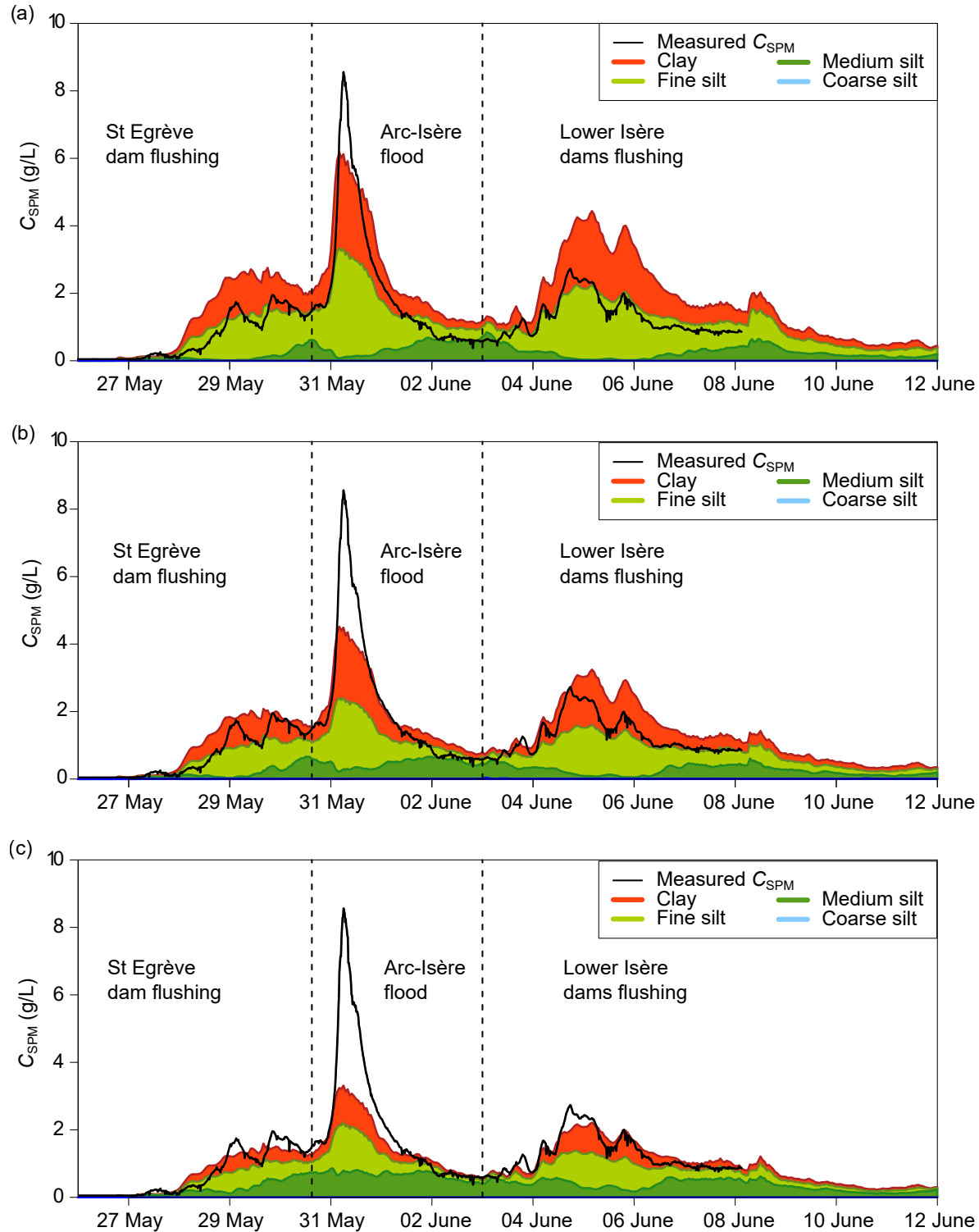

Figure 6: Simulated and measured SPM concentration $\left(C_{\mathrm{SPM}}\right)$ at Viviers station for the three hypothetical GSD defined in Tab. 2: (a) Mixture A - Fine, (b) Mixture B - Medium and (c) Mixture C - Coarse.

Simulation tests also confirm that the GSD of the SPM transported was

different during the three periods of the May-June 2008 flood event. During the 
St Egrève Dam flushing period, the model using medium or coarse GSD (Mixtures $\mathrm{B}$ or $\mathrm{C}$ ) yields $C_{\mathrm{SPM}}$-values in relatively good agreement with measured data. Mixture B was eventually preferred since it corresponds to measured data during the flood period of a similar event (in 2015). Also, it yields a better estimation of peak concentrations. Flushing operation evacuated the coarse SPM from the St Egrève reservoir, but they were partially stored into the Lower Isère reservoirs, as the Lower Isère dams were operated with high water levels during this period. This could explain why the medium GSD is consistent with this situation.

During the Arc-Isère flood period, the $C_{\mathrm{SPM}}$ peak measured at Viviers reached about $9 \mathrm{~g} / \mathrm{L}$. Mixture A yielded the best agreement between simulated and measured $C_{\mathrm{SPM}}$ time series. Such very fine washload material, poorly represented in the bed, is brought from the Isère basin by the flood wave. Nevertheless, the simulated $C_{\mathrm{SPM}}$ peak reached only $6 \mathrm{~g} / \mathrm{L}$. As discussed above, the concentration peak at Beaumont-Monteux should have been higher and narrower. Using a finer GSD could also increase the simulated $C_{\mathrm{SPM}}$ peak. However, as discussed in section 3.3, a finer GSD would no longer correspond to the samples measured in the Isère River during floods of the Arc River.

For the third period of the event, corresponding to the Lower Isère dams flushing, Mixture $\mathrm{C}$ yields $C_{\mathrm{SPM}}$ at Viviers station that are in best agreement with measurements. This is consistent with the opening of the dam gates and the resuspension of coarser particles previously settled in the reservoir.

According to these observations, the GSD was parametrized as follows for the simulation of the May-June 2008 flood event: the medium GSD of Mixture B for the first period, the fine GSD of Mixture A for the second period and the coarse GSD of Mixture C for the third period.

\subsection{Interaction of SPM with hydropower schemes}

The objective of this section is to study the SPM dynamics in interaction of SPM with hydropower schemes between the lowest Isère dam and Viviers station (Fig. 1). Five additional simulations were carried out to study the de- 
position/erosion processes occurring in each hydropower scheme of the reach. The first simulation was run without activating deposition/erosion within the entire river system. In the other four simulations, deposition/erosion was successively activated in the four hydropower schemes of the system, which led to the decrease of the $C_{\mathrm{SPM}}$ simulated at Viviers (Fig. 7). Simulation of deposition is necessary to reproduce the $C_{\mathrm{SPM}}$ measured at Viviers. The simulated $C_{\mathrm{SPM}}$ peak decreased from 4 to $2 \mathrm{~g} / \mathrm{L}, 9$ to $6 \mathrm{~g} / \mathrm{L}$, and 8 to $2 \mathrm{~g} / \mathrm{L}$ in the first, second, and third period, respectively. This confirms that hydropower schemes are an obstacle to SPM transport due to the decreased flow velocity in dam reservoirs, which enhances deposition particularly for coarse SPM. Deposition is particularly intense during the dam flushing periods (first and third periods), as coarser GSD was parameterized for these periods (see section 4.2). These simulations also suggest that the largest decrease of $C_{\mathrm{SPM}}$ occurred in the Bourg-lès-Valence (BLV) scheme, between the lowest Isère dam and BLV dam. SPM also settled down within the next three hydro-electric schemes, but to a lesser extent since most of the coarsest particles settled down in the first scheme.

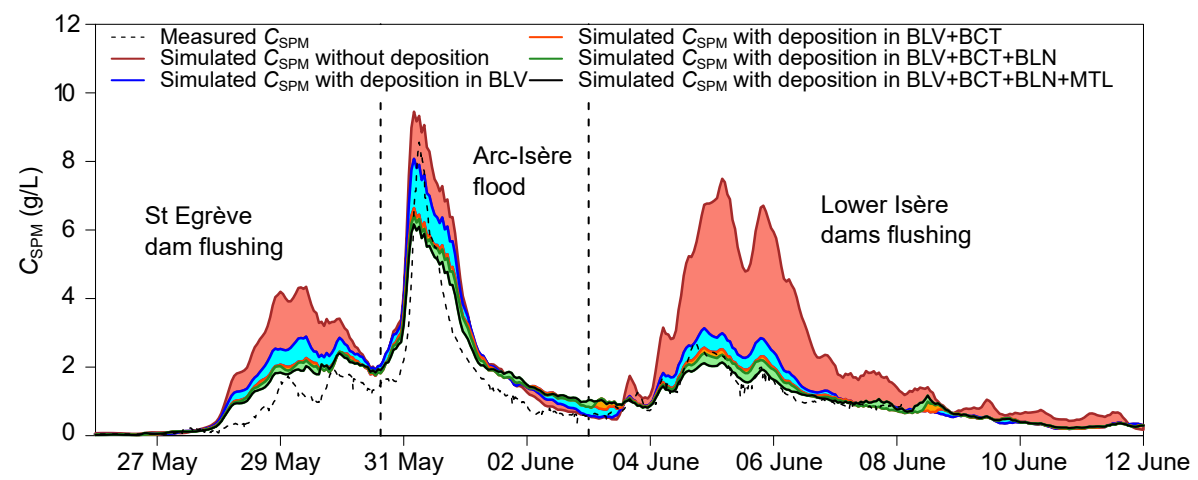

Figure 7: Measured and simulated SPM concentration $\left(C_{\mathrm{SPM}}\right)$ at Viviers station during the May-June 2008 flood event, with deposition/erosion processes successively activated in the four hydropower schemes located between the lowest Isère dam and Viviers. BLV = Bourglès-Valence, BCT $=$ Beauchastel, BLN $=$ Baix-Le Logis Neuf, MTL $=$ Montélimar. Coloured areas represent the cumulative SPM trapped in successive reservoirs.

The numerical model provides detailed information on the quantity and grain 
size distribution of the SPM present in each branch of the river system at any time of the simulation. In order to better understand the deposition processes between the lowest Isère dam and the BLV dam observed in Fig. 7, the cumulative amounts of SPM settled in the area are presented in Fig. 8. At the scale of the entire event, the Isère River produced a total amount of 7.7 Mt of SPM, of which 2.8 Mt deposited at the Isère-Rhône confluence (Fig. 8d). The SPM deposition occurred mainly within three branches of the network: $60 \%$ in the lowest Isère branch, and 30\% in the BLV and Beauchastel (BCT) power canals. Deposition mainly occurred during the second and third periods with a segregation in the grain size of the particle deposited, as also observed by Camenen et al. (2019). The Isère River produced 2.8 Mt during the second period, and $80 \%$ of this input, mainly composed of fine SPM, travelled through the BLV and BCT schemes. The remaining 20\%, mainly composed of class 3 particles, were trapped in the $\mathrm{BCT}$ and $\mathrm{BLV}$ power canals, and not in the lowest Isère branch. But most of the deposition occurred during the third period when the Lower Isère dams were flushed. The SPM flux during this period was $3.8 \mathrm{Mt}$, i.e. half of the total input of the Isère during the event. SPM of class 4 represented $30 \%$ of the Isère River input, and these particles massively deposited within the Isère branch, and to a lesser extent within the BLV and BCT power canals. The deposits simulated in the downstream Isère reach are mainly composed of classes 3 and 4, which is consistent with available observations and with the choice of Mixture C as a coarse GSD representative of a deposit collected after the May 2015 flood. 
Author-produced version of the article published in Launay, M., Dugué, V., Faure, J.-B., Coquery, M., Camenen, B., Le Coz, J. (2019)

Numerical modelling of the suspended particulate matter dynamics in a regulated river network, Science of the Total Environment, $665,591-605$, DOI : 10.1016/j.scitotenv.2019.02.015

(a)

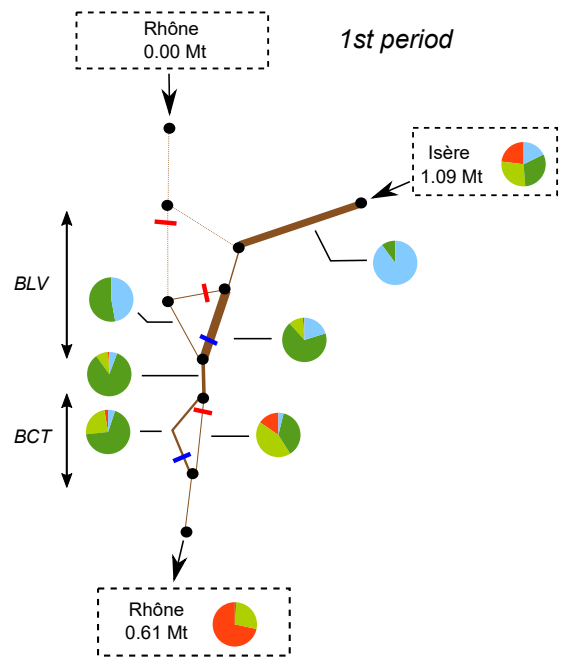

(c)

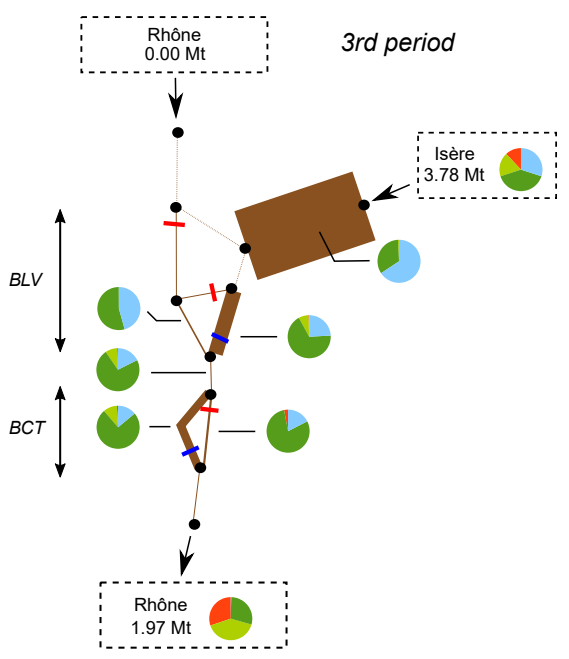

(b)

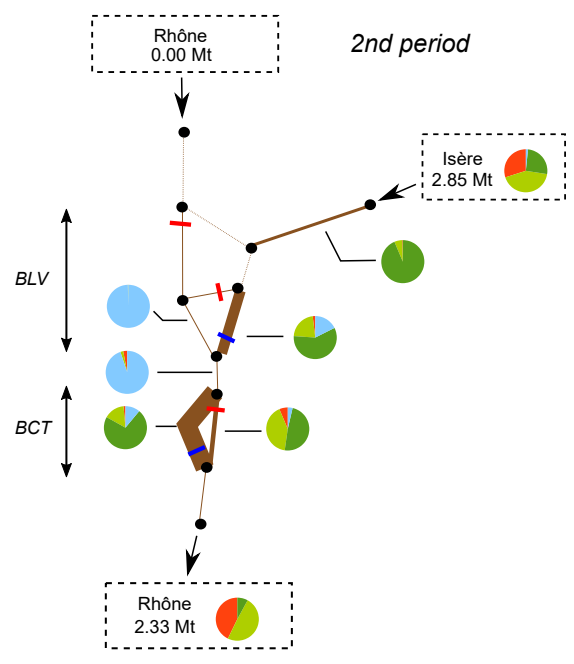

(d)

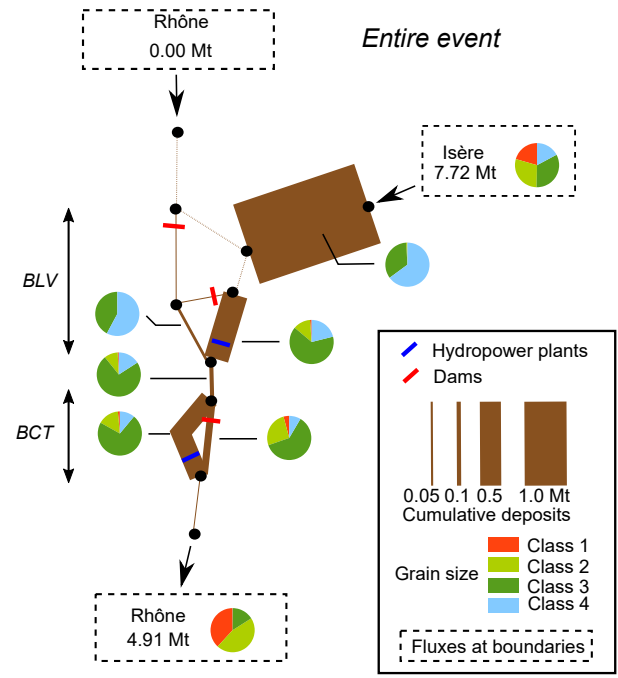

Figure 8: Mass and grain size composition of SPM deposited in the Isère-Rhône confluence system during the May-June 2008 flood event: first period (a), second period (b), third period (c) and entire event (d). See section 2.2 for definition of periods and Tab.2 for definition of grain size classes. The mass and grain size composition of SPM fluxes at boundaries are also shown. The thickness of the lines is proportional to the mass of SPM deposited in each reach. $\mathrm{BLV}=$ Bourg-lès-Valence scheme and BCT $=$ Beauchastel scheme. 


\subsection{Cumulative SPM fluxes}

Measured and simulated SPM cumulative fluxes are presented in Tab. 3 and Fig. 9 for the three periods (see section 2.2) and for the entire May-June 2008 flood event at the monitoring stations in the Rhône River. In Fig. 9, the lefthand graphs display the cumulative fluxes estimated from observations whereas the right-hand graphs display the cumulative fluxes specified or simulated in the numerical model.

The relative deviation between the simulated and measured SPM cumulative fluxes was between $+15 \%$ and $+36 \%$ (see Tab. 3), except for the first period for which larger values are observed since measured cumulative fluxes are small. At Viviers station, the absolute deviation was around $+0.8 \mathrm{Mt}$ for the entire event for a total measured SPM flux of 3.6 Mt at this station. This relatively small deviation validates the reconstruction of the $C_{\mathrm{SPM}}$ time series at BeaumontMonteux described in section 2.3, and the choice of the varying GSD for the three periods (see section 4.2). At Arles station, the measured SPM flux for the entire event was $4.2 \mathrm{Mt}$, and the simulated SPM flux was $5.7 \mathrm{Mt}$. Eyrolle et al. (2012) estimated this flux to be $4.7 \mathrm{Mt} \pm 30 \%$. These results are of the same order of magnitude and confirm the exceptional nature of the May-June 2008 flood event.

As for the Durance River, the model highlighted the weakness of the hypothesis made of a very fine grain size distribution for the entire event. During the first week of the event, the relative deviation between measured and simulated fluxes increased from $+50 \%$ to $+133 \%$ between Viviers and Beaucaire (see Tab. 3). This is explained by the transfer of the SPM of the Durance directly to Beaucaire without deposition because of a too fine grain size distribution assumed for the Durance River SPM input during this first period. The measured SPM flux of 0.5 Mt only at Beaucaire during the first week indicated a large deposition of around 1.0 Mt at the Durance confluence. For the second and third periods, the hypothesis of a fine GSD for the Durance SPM input appeared more realistic although still a little bit too fine as the measured and simulated fluxes at Beaucaire were in better agreement. The fine SPM coming from the 
Table 3: Measured and simulated SPM cumulative fluxes for the three periods (see section 2.2) and for the entire May-June 2008 flood event at the monitoring stations in the Rhône River, and relative deviations (RD) of the simulated fluxes to the measured flux.

\begin{tabular}{cccccccccc}
\hline & \multicolumn{3}{c}{ Rhône at Viviers } & \multicolumn{3}{c}{ Rhône at Beaucaire } & \multicolumn{3}{c}{ Rhône at Arles } \\
\hline & Meas. & Model & RD & Meas. & Model & RD & Meas. & Model & RD \\
& Mt & Mt & $\%$ & Mt & Mt & $\%$ & Mt & Mt & $\%$ \\
\hline Period 1 & 0.4 & 0.6 & +50 & 0.6 & 1.4 & +133 & 0.5 & 1.2 & +140 \\
Period 2 & 1.9 & 2.2 & +16 & 2.6 & 3.0 & +15 & 2.2 & 2.6 & +18 \\
Period 3 & 1.3 & 1.6 & +23 & 1.7 & 2.1 & +24 & 1.5 & 1.9 & +27 \\
Total & 3.6 & 4.4 & +22 & 4.9 & 6.5 & +33 & 4.2 & 5.7 & +36 \\
\hline
\end{tabular}

Durance River during these two periods seemed to have travelled through the downstream Durance reach and Rhône River down to the Delta with limited deposition. For the downstream Durance reach, this also could be explained during the second period because of the much higher discharges and velocities.

The model was also useful for estimating the amount of SPM transported in the Petit Rhône at Fourques, where no $C_{\mathrm{SPM}}$ measurement were available. The SPM flux of the Petit Rhône represented from 10 to $15 \%$ of the SPM fluxes measured at Beaucaire station. This is in good agreement with the water discharge distribution between the Petit Rhône and the Grand Rhône observed in long-term discharge time series (source CNR). 
Author-produced version of the article published in Launay, M., Dugué, V., Faure, J.-B., Coquery, M., Camenen, B., Le Coz, J. (2019)

Numerical modelling of the suspended particulate matter dynamics in a regulated river network, Science of the Total Environment, $665,591-605$, DOI : 10.1016/j.scitotenv.2019.02.015
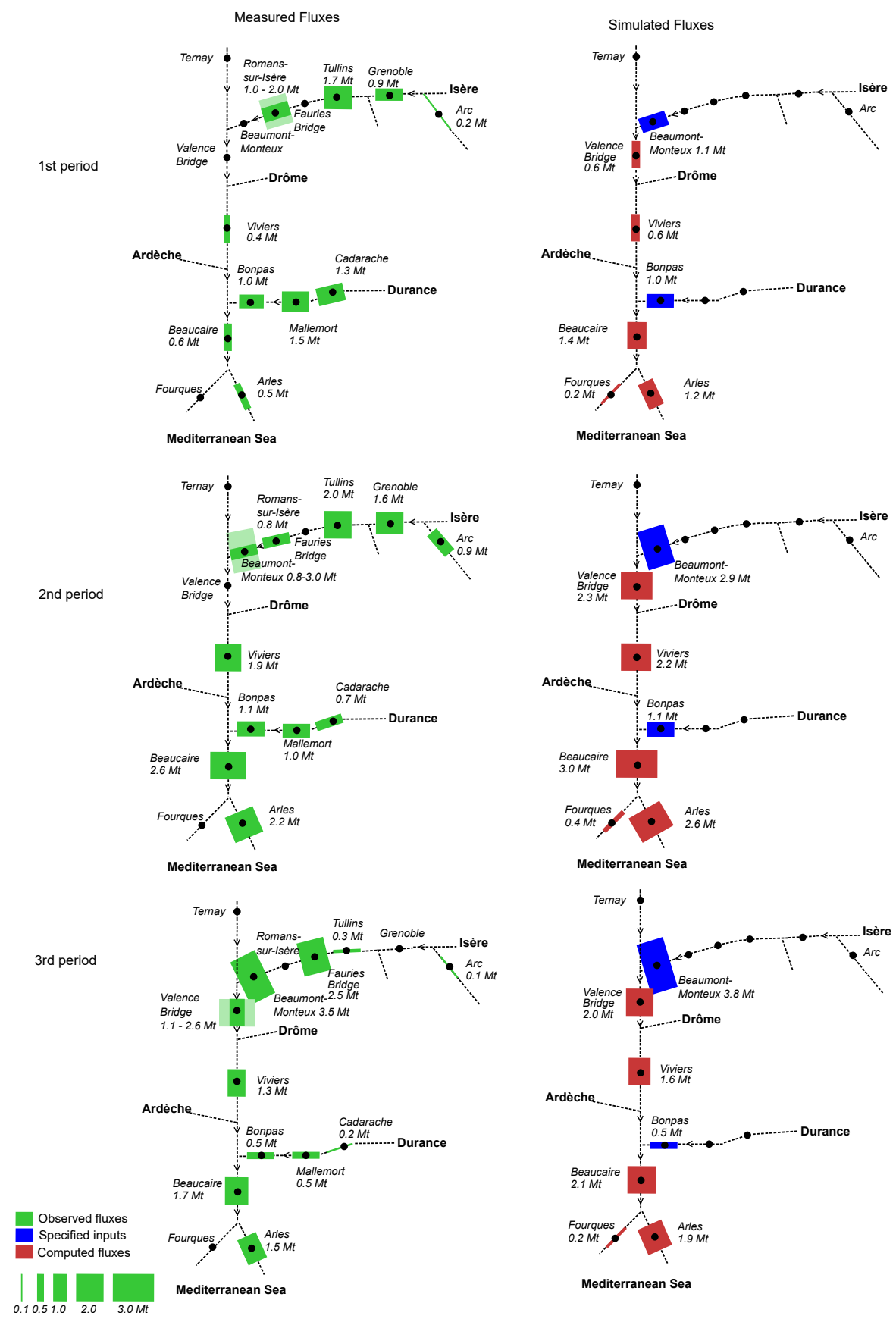

Figure 9: Monitored and simulated SPM cumulative fluxes (in Mt) along the Rhône River during the first, second and third periods of the 2008 flood event. Line thickness is proportional to SPM flux at the corresponding station. 


\subsection{Origin of the $S P M$}

The origin of the SPM transported during the three periods of the event and measured at Arles was clarified. In particular, the Isère River input that was not measured during the first period could be quantified with the model. Fig. 10 shows the evolution of the measured and simulated $C_{\mathrm{SPM}}$ at Arles and the proportion of SPM coming from both the Isère and the Durance Rivers. The simulated $C_{\mathrm{SPM}}$ are close to the measured $C_{\mathrm{SPM}}$, except the $C_{\mathrm{SPM}}$ peak recorded on $01 / 06 / 2008$. The maximum recorded $C_{\text {SPM }}$ was about $5 \mathrm{~g} / \mathrm{L}$ while the maximum simulated $C_{\text {SPM }}$ was $4 \mathrm{~g} / \mathrm{L}$, being a difference of $20 \%$. Fig. 10 highlights the high contribution of the Durance River during the first days of the event, and the increasing contribution of the Isère River during the rest of the event. Approximately $50 \%$ of the SPM fluxes came from the Durance River and the remaining $50 \%$ came from the Isère River. Marion et al. (2010) and Eyrolle et al. (2012) discussed the origin of the SPM transited and deposited in the Grand-Rhône pro-delta during the May-June 2008 event. They assumed that most of the SPM came from the Durance River, therefore they investigated the origin of the SPM within the Durance river basin and ignored the equally large contribution of the Isère River.

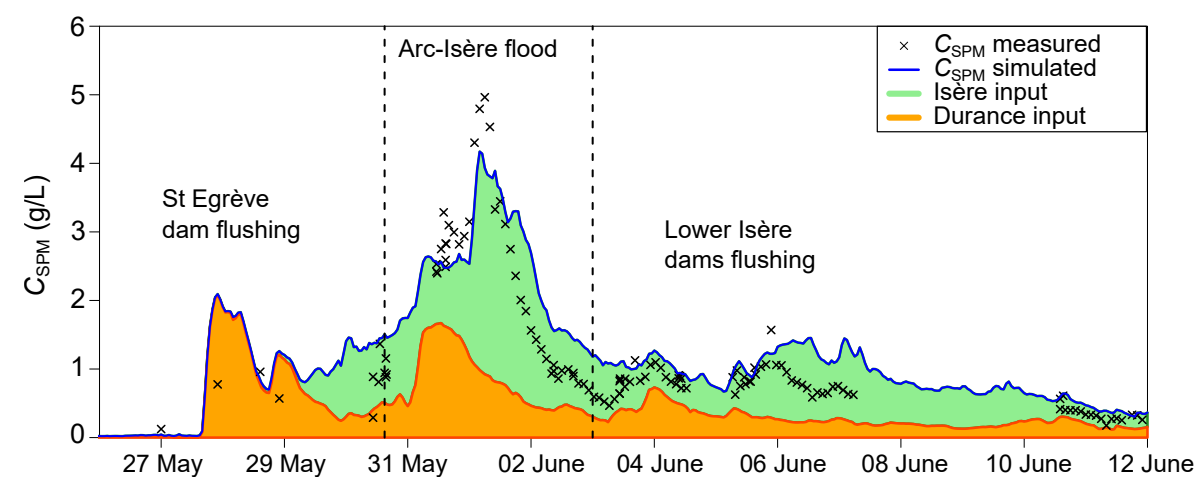

Figure 10: Simulated and measured $C_{\mathrm{SPM}}$ in the Rhône at Arles during the May-June 2008 flood event with decomposition of the Isère and Durance Rivers SPM inputs.

Nearly $50 \%$ of the SPM flux brought by the Isère River to the Rhône 
River system deposited in the river network before reaching Viviers. Although the model confirmed that the Rhône reservoirs acted as sediment sinks during the May-June 2008 flood event, they can turn to act as sediment sources due to resuspension during other floods. In the annual SPM fluxes computed by Poulier et al. (2019), there is evidence that the SPM deposited and stored during the 2008 event were later re-suspended and exported during floods.

\section{Conclusive comments}

This paper explores the potential of numerical simulation to predict the sources and fate of SPM in regulated river networks. The main questions on numerical simulation tools addressed through this case study were: What is the added value of 1-D modelling of SPM fluxes? What are the most sensitive parameters? What are the main limitations and perspectives for improvement?

A 1-D hydrodynamical model was built and applied to a major hydrosedimentary event in May-June 2008 in the Lower Rhône River, France. Such model would be the simplest and fastest possible hydrodynamical model that could be constructed and some physical processes that may be important are neglected in exchange for that simplicity. The Rhône River has a complex river network with confluences, bifurcations and hydropower schemes. The simulation code (AdisTS) was able to model the SPM fluxes at a high spatial and temporal resolution, which is useful to understand the SPM dynamics over the whole river system on time scales ranging from hour to decades, thanks to fast computational times. Especially, SPM supplies from the main tributaries and deposition of the coarsest particles behind hydropower structures could be quantified precisely, at any time and at any cross-section of the river network. The model provides insights that are not available from observational data alone. Especially, the model simulates the continuous dynamics and spatial distribution of deposits, which would have allowed a better anticipation and management of sedimentation in critical areas of the Rhône reservoirs.

In the presented study case, approximately half of the $4.9 \mathrm{Mt}$ of SPM mea- 
sured at the outlet of the Rhône River catchment during the event were found to come from the Isère River and the other half from the Durance River whereas previous studies estimated that most of the flux at the outlet came from the Durance River. Also, the model confirmed that a large amount of the SPM delivered by the Isère River was trapped behind the first hydro-electric scheme in the Rhône River, a cause of conflicts between dam operators. The high temporal and spatial resolution of fluxes computation is highly valuable for reconstructing past events and also for managing future events like natural floods or dam flushing operations, by testing multiple dam operation scenarios. If forecasts of water discharges and SPM inputs are available, such a model can be used to compute real-time forecasts of SPM concentrations, fluxes and deposition throughout the river network.

As a basis for hydraulic simulation, an accurate description of the channel geometry and of the artificial structures is necessary, along with a conventional calibration of the friction coefficients along the river stretches. This was easily achieved in our case study. As for SPM simulation, the quality of the numerical results was found to be highly sensitive to suspended sediment parameters, especially grain size, and to the operational rules of artificial structures. This may lead to substantial errors because accurate information on grain size distribution is often difficult to obtain, grain size varies spatially and temporally, and the coarsest particles may not be homogeneously distributed throughout the river cross-section. In this study, sensitivity tests made on the grain size distribution of the SPM improved our knowledge of the Isère River input, despite the lack of measurements. Finer SPM particles were mostly transported during the natural flood period while coarser SPM were transported during the dam flushing periods. The simulation of deposition and erosion processes within the hydropower schemes was necessary to reproduce the strong deposition of SPM at the Isère confluence and further downstream. Deposits were mainly composed of the coarsest SPM (cf. Camenen et al., 2019), while finer SPM travelled through the hydropower schemes without settling down.

Of course, observation and modelling supplement each other: dense and 
precise SPM observational data measured at key points of the river system are necessary to specify the boundary conditions of numerical models, and to calibrate and validate them. An extended sensitivity analysis could be done to better infer upstream sediment supply, i.e. input concentrations and GSD. In the present paper, we constrained the tests to prior knowledge based on actual measurements and uncertainties. Another perspective of this work is to compare 1-D numerical modelling with chemical fingerprinting for quantifying SPM sources in the Rhône River for various hydrological conditions.

The 1-D numerical model applied in this study is typical of modern simulation tools used in river engineering applications. While the principles of 1-D hydrodynamical codes have virtually not changed for fifty years or so, their computation performance and the power of the available computers have been greatly improved. Compared to 2-D or 3-D hydrodynamical codes, 1-D hydrodynamical codes offer much faster computational times allowing for real-time or long-term simulations and uncertainty analysis through Monte Carlo simulation or sensitivity analysis (Souhar and Faure, 2009), which is practically challenging with higher level codes. The spatial resolution of 1-D hydrodynamical codes is sufficient for studying SPM dynamics on the river network scale, while 2-D or 3-D hydrodynamical codes would be required for studying local processes, in the close vicinity of artificial structures for instance. However, most 1-D hydrodynamical codes still come with restrictive assumptions that call to be improved through future research. Computing the flow and suspended sediment flux interactions between the main channel and the floodways, or floodplains, is still motivating active research. More generally, the spanwise distribution of velocities, SPM concentrations and deposition/erosion fluxes throughout crosssections has to be predicted from 1-D, i.e. cross-sectional average results. A major limitation of 1-D hydrodynamical codes is the usual assumption of full, instantaneous mixing of water and SPM downstream of confluences. In the case of the Rhône River, full mixing after a confluence is actually seldom reached before the next bifurcation between the navigation canal and the by-passed channel of the Old Rhône. Formulas for predicting the degree of mixing and the 
spanwise distribution of SPM concentrations still have to be elaborated, based on tracing experiments conducted in the laboratory and in the field.

\section{Acknowledgments}

This study was conducted within the Rhône Sediment Observatory (OSR), a multi-partner research program funded through the Plan Rhône by the European Regional Development Fund (ERDF), Agence de l'eau RMC, CNR, EDF and three regional councils (Auvergne-Rhône-Alpes, PACA and Occitanie). The PhD scholarship of Marina Launay (2010-2014) was funded by the Rhône-Alpes regional council. Authors also thank many collaborators at Irstea, Cerege, IRSN, MIO and Ifremer for their contributions to the field work and the chemical analyses. This work builds on the developments of earlier versions of the 1-D Rhône model achieved by Emilie Andriès and Carla Walter (Irstea).

\section{References}

AFNOR (2005), NF EN 872 : Water quality - Determination of suspended solids - Method by filtration through glass fibre filters (in French), 10 p.

Armanini, A., and G. Di Silvio (1988), A one-dimensional model for the transport of a sediment mixture in non-equilibrium conditions, $26(3), 275-292$, doi:10.1080/00221688809499212.

Camenen, B. (2007), Simple and general formula for the settling velocity of particles, Journal of Hydraulic Engineering-ASCE, 133, 229-233, doi:10.1061/ (ASCE)0733-9429(2007)133:2(229).

Camenen, B., E. Perret, A. Herrero, C. Berni, F. Thollet, A. Buffet, G. Dramais, C. Le Bescond, and M. Lagouy (2016), Estimation of the volume of a fine sediment deposit over a gravel bar during a flushing event, in River Flow 2016, CRC Press, pp. 533-540. 
Camenen, B., G. Naudet, G. Dramais, J. Le Coz, and A. Paquier (2019) A multitechnique approach for evaluating sand dynamics in a complex engineered piedmont river system, Science of the Total Environment, 657, 485-497, doi: 10.1016/j.scitotenv.2018.11.394.

Clifford, N., K. Richards, R. Brown, and S. Lane (1995), Laboratory and field assessment of an infrared turbidity probe and its response to particle-size and variation in suspended sediment concentration, Hydrological Sciences Journal, 40(6), 771-791, doi:10.1080/02626669509491464.

Copard, Y., F. Eyrolle, O. Radakovitch, A. Poirel, P. Raimbault, S. Gairoard, and C. Di-Giovanni (2018) Badlands as a hot spot of petrogenic contribution to riverine particulate organic carbon to the Gulf of Lion (NW Mediterranean Sea), Earth Surface Processes and Landforms, in press, doi:10.1002/esp.4409

Druine, F., R. Verney, J. Deloffre, J.P. Lemoine, M. Chapalain, V. Landemaine, and R. Lafite (2018), In situ high frequency long term measurements of suspended sediment concentration in turbid estuarine system (Seine Estuary, France): Optical turbidity sensors response to suspended sediment characteristics, Marine Geology, 400, 24-37

Dugué, V., C. Walter, E. Andries, M. Launay, J. Le Coz, B. Camenen, and J.-B. Faure (2015), Accounting for hydropower schemes' operation rules in the 1D hydrodynamic modeling of the Rhône River from Lake Geneva to the Mediterranean Sea, in E-proceedings of the 36th IAHR World Congress, 28 June - 3 July, 2015, The Hague, The Netherlands, p. 9.

El Kadi Abderrezzak, K., and A. Paquier (2009), One-dimensional numerical modeling of sediment transport and bed deformation in open channels, Water Resources Research, 45(5), doi:10.1029/2008\{WR\}007134, W05404.

Eyrolle, F., O. Radakovitch, and P. Raimbault (2012), Consequences of hydrological events on the delivery of suspended sediment and associated radionuclides from the Rhône River to the Mediterranean Sea, Journal of Soils and Sediments, 12, 1479-1495, doi:10.1007/s11368-012-0575-0. 
Foster, I., R. Millington, and R. Grew (1992), The impact of particle size controls on stream turbidity measurement; some implications for suspended sediment yield estimation, Erosion and sediment transport monitoring programmes in river basins, 210, 51-62.

Garneau, C., S. Sauvage, A. Probst, and J. Sánchez-Pérez (2015), Modelling of trace metal transfer in a large river under different hydrological conditions (the Garonne River in southwest France), Ecological Modelling, 306 (Supplement C), 195 - 204, doi:https://doi.org/10.1016/j.ecolmodel.2014. 09.011.

Gippel, C. (1995), Potential of turbidity monitoring for measuring the transport of suspended-solids in streams, Hydrological Processes, 9(1), 83-97, doi:10. 1002/hyp.3360090108.

Gray, J. and J. Gartner (2010)., Technological advances in suspended-sediment surrogate monitoring, Water Resources Research, 46(4):W00D29

Guertault, L. (2015), Evaluation of the hydro-sedimentary processes of an elongated dam reservoir: Application to the Génissiat reservoir located on the Upper-Rhône River (in French), PhD, Université Claude Bernard Lyon 1, Lyon, France, 239 p.

Guertault, L., B. Camenen, C. Peteuil, A. Paquier, and J.-B. Faure (2016), OneDimensional Modeling of Suspended Sediment Dynamics in Dam Reservoirs, Journal of Hydraulic Engineering-ASCE, 142(10), doi:10.1061/(\{ASCE $\}$ ) $\{\mathrm{HY}\} .1943-7900.0001157$.

Han, Q. (1980), A study on the non-equilibrium transportation of suspended load, in 1st Int. Symp. on River Sedimentation, Chinese Society of Hydraulic Engineering, China, pp. 793-802.

Horner I., B. Renard, J. Le Coz, F. Branger, H.K. McMillan, and G. Pierrefeu (2018), Impact of stage measurement errors on streamflow uncertainty, Water Resources Research, 54, 1952-1976. 
Horowitz, A. (2008), Determining annual suspended sediment and sedimentassociated trace element and nutrient fluxes, Science of the Total Environment, 400(1-3), 315-343, doi:10.1016/j.scitotenv.2008.04.022.

Horowitz, A., K. Elrick, and J. Smith (2001), Estimating suspended sediment and trace element fluxes in large river basins: methodological considerations as applied to the NASQAN programme, Hydrological Processes, 15(7), 11071132, doi:10.1002/hyp.206.

Horowitz, A. J., R. T. Clarke, and G. H. Merten (2015), The effects of sample scheduling and sample numbers on estimates of the annual fluxes of suspended sediment in fluvial systems, Hydrological Processes, 29(4), 531-543, doi:10. 1002/hyp.10172.

Iwasa, Y., and S. Aya (1991), Predicting longitudinal dispersion coefficient in open channel flows, in Int. Symp. on Environmental Hydraulics, IAHR, HongKong, China, pp. 505-510.

Kondolf, G.M., Y. Gao, G.W. Annandale, G.L. Morris, E. Jiang, J. Zhang, Y. Cao, P. Carling, K. Fu, Q. Guo, R. Hotchkiss, C. Peteuil, T. Sumi, H.W. Wang, Z. Wang, Z. Wei, B. Wu, C. Wu, and C.T. Yang (2015), Sustainable sediment management in reservoirs and regulated rivers: Experiences from five continents, Earth'Future, 2, 1 - 25, doi:http://dx.doi.org/10.1002/ $2013 \mathrm{EF} 000184$.

Krone, R. (1962), Flume studies of the transport of sediment in estuarial shoaling processes: final report, Tech. rep., Hydraulic Eng. Lab. and Sanitary Eng. Res. Lab., University of California, Berkeley, California, USA, 110 p.

Launay, M. (2014), Fluxes of suspended particulate matters, particulate mercury and PCBs in the Rhône River, from Lake Geneva to the Mediterranean Sea (in French), PhD, Claude Bernard University Lyon 1, Lyon, France, $432 \mathrm{p}$. 
Launay, M., J. Le Coz, B. Camenen, C. Walter, H. Angot, G. Dramais, J.B. Faure, and M. Coquery (2015), Calibrating pollutant dispersion in 1-D hydraulic models of river networks, Journal of Hydro-Environment Research, 9(1), 120 - 132, doi:http://dx.doi.org/10.1016/j.jher.2014.07.005.

Legout, C., I.A. Droppo, J. Coutaz, C. Bel, and M. Jodeau (2018), Assessment of erosion and settling properties of fine sediments stored in cobble bed rivers: the Arc and Isère alpine rivers before and after reservoir flushing, Earth Surface Processes and Landforms, 43(6), 1295 - 1309, doi: http://dx.doi.org/10.1002/esp.4314.

Ludwig, W., E. Dumont, M. Meybeck, and S. Heussner (2009), River discharges of water and nutrients to the Mediterranean and Black Sea: Major drivers for ecosystem changes during past and future decades? Progress in Oceanography, 80(3-4), 199 - 217, doi:https://doi.org/10.1016/j.pocean.2009.02.001.

Mano, V., J. Nemery, P. Belleudy, and A. Poirel (2008), One year of suspended particle matter (SPM) and carbon fluxes on an alpine river : the Isere River (in French), La Houille Blanche, (5), 64 p.

Marion, C., G. Maillet, M. Arnaud, and F. Eyrolle (2010), Quantification of the Rhône solid fluxes at the mouth: contributions of the Durance River during the exceptional flood of May 2008 (in French), La Houille Blanche, (5), 72-80, doi:10.1051/lhb/2010057.

Masson, M., H. Angot, C. Le Bescond, M. Launay, A. Dabrin, C. Miège, J. Le Coz, and M. Coquery (2018), Sampling of suspended particulate matter using particle traps in the Rhône River: Relevance and representativeness for the monitoring of contaminants, Science of the Total Environment, 637-638, 538549, doi:10.1016/j.scitotenv.2018.04.343.

Moatar, F., M. Meybeck, S. Raymond, A. Coynel, W. Ludwig, V. Mano, J. Nemery, A. Poirel, H. Etcheber, and P. Crouzet (2008), SPM fluxes estimates from discrete monitoring: comparison of calculation methods and uncertainities, La Houille Blanche, (4), 64-71. 
Moore, S. A., J. Le Coz, D. Hurther, and A. Paquier (2012), On the Application of Horizontal ADCPs to Suspended Sediment Transport Surveys in Rivers, Continental Shelf Research, 46, 50-63.

Moore, S. A., J. Le Coz, D. Hurther, and A. Paquier (2013), Using multifrequency acoustic attenuation to monitor grain size and concentration of suspended sediment in rivers, Journal of the Acoustical Society of America, 133(4), 1959-1970, doi:\{10.1121/1.4792645\}.

Navratil, O., O. Evrard, M. Esteves, C. Legout, S. Ayrault, J. Nemery, A. Mate Marin, M. Ahmadi, I. Lefevre, A. Poirel, and P. Bonte (2012), Temporal variability of suspended sediment sources in an alpine catchment combining river/rainfall monitoring and sediment fingerprinting, Earth Surface Processes and Landforms, 37(8), 828-846, doi:10.1002/esp.3201.

Nicollet, G., and M. Uan (1979), Permanent flows with free surface in compounds beds (in French), La Houille Blanche, 1, 21-30.

Ollivier, P., B. Hamelin, and O. Radakovitch (2010), Seasonal variations of physical and chemical erosion: A three-years survey of the Rhone river (France), Geochimica et Cosmochimica Acta, 74(no 3), 907-927.

Papanicolaou, A. T. N., M. Elhakeem, G. Krallis, S. Prakash, and J. Edinger (2008), Sediment Transport Modeling Review: Current and Future Developments, Journal of Hydraulic Engineering-ASCE, 134(1), 1-14, doi: 10.1061/(\{ASCE\})0733-9429(2008)134:1(1).

Pardé, M. (1925), The hydrological regime of the Rhône River (in French). Institut de Géographie Alpine, vol. 13:3, 459-547 pp.

Partheniades, E. (1965), Erosion and deposition of cohesive soils, Journal of Hydraulic Division, 91, 105-139.

Phillips, J., B. Webb, D. Walling, and G. Leeks (1999), Estimating the suspended sediment loads of rivers in the LOIS study area using infrequent samples, Hydrological Processes, 13(7), 1035-1050. 
Pont, D. (1997), The discharge of suspended sediments near to the mouth of the Rhône recent statistics (1994-1995) (in French), Revue de Géographie de Lyon, 72(1), 23-33, doi:10.3406/geoca.1997.4675.

Pont, D., J. Simonnet, and A. Walter (2002), Medium-term changes in suspended sediment delivery to the ocean: Consequences of catchment heterogeneity and river management (Rhone River, France), Estuarine Coastal and Shelf Science, 54(1), 1-18, doi:10.1006/ecss.2001.0829.

Poulier, G., M. Launay, C. Le Bescond, F. Thollet, M. Coquery, and J. Le Coz (2019), Combining flux monitoring and data reconstruction to establish annual budgets of suspended particulate matter, mercury and PCB in the Rhône River from Lake Geneva to the Mediterranean Sea, Science of the Total Environment, 658, 457-473, doi:10.1016/j.scitotenv.2018.12.075.

Radakovitch, O., V. Roussiez, P. Ollivier, W. Ludwig, C. Grenz, and J.-L. Probst (2008), Input of particulate heavy metals from rivers and associated sedimentary deposits on the Gulf of Lion continental shelf, Estuarine, Coastal and Shelf Science, $77(2), 285-295$.

Rieux, C. (2008), Report of the Lower Isère dam flushing. Results of the physicochemical monitoring from 2 to 12 of June 2008 (in French), Tech. Rep. D4161/RAP/2008-00653-A, EDF, 29 p.

Souhar, O., and J.-B. Faure (2009), Approach for uncertainty propagation and design in Saint-Venantequations via automatic sensitive derivatives applied to Saar river, Canadian Journal of Civil Engineering, 36(7), 1144-1154.

Thollet, F., J. Le Coz, G. Antoine, P. François, L. Saguintaah, M. Launay, and B. Camenen (2013), Influence of grain size changes on the turbidity measurement of suspended solid fluxes in watercourses (in French), La Houille Blanche, 4, 50-56.

Ulke, A., G. Tayfur, and S. Ozkul (2017), Investigating a suitable empirical model and performing regional analysis for the suspended sediment load pre- 
diction in major rivers of the Aegean region, Turkey, Water Resources Management, 31(3), 739-764, doi:10.1007/s11269-016-1357-z.

Walling, D., and B. Webb (1985), Estimating the discharge of contaminants to coastal waters by rivers - some cautionary comments, Marine Pollution Bulletin, 16(12), 488-492, doi:10.1016/0025-326\{X\}(85)90382-0.

Walling, D., P. Owens, J. Carter, G. Leeks, S. Lewis, A. Meharg, and J. Wright (2003), Storage of sediment-associated nutrients and contaminants in river channel and floodplain systems, Applied Geochemistry, 18(2), 195-220.

Wu, W., D. A. Vieira, and S. S. Y. Wang (2004), One-Dimensional Numerical Model for Nonuniform Sediment Transport under Unsteady Flows in Channel Networks, Journal of Hydraulic Engineering-ASCE, 130(9), 914-923, doi:10. 1061/(\{ASCE\})0733-9429(2004)130:9(914). 